\title{
Periodontal complications with obesity
}

\author{
Jean E. Suvan ${ }^{1}$ | Nicholas Finer ${ }^{2}$ | Francesco D'Aiuto ${ }^{1}$ \\ ${ }^{1}$ Unit of Periodontology, UCL Eastman Dental Institute, London, UK \\ ${ }^{2}$ National Centre for Cardiovascular Prevention and Outcomes, UCL Institute of Cardiovascular Science, London, UK \\ Correspondence \\ Jean E. Suvan \\ Email: j.suvan@ucl.ac.uk
}

\section{1 | CONTEXT OF THE REVIEW}

In recent decades, science and technology have demonstrated profound advancements, bringing changes to society not seen since the industrial revolution. Average life expectancy has increased from 50 years of age in 1913 to 81.2 years of age in 2015, an increase of nearly 3 years per decade over the last 100 years. ${ }^{1}$ Many infectious diseases have become almost extinct. In spite of all this, medicine continues to face unparalleled health challenges. The last century was dominated by infectious agents and discoveries of antibiotics tc combat them, and now, well into the present century, the focus of medicine is on the human body's interaction with the world arounc us. Longer lives, together with increased understanding of biologica concepts, new biomaterials, advanced diagnostic tools, and therapeutic techniques, have brought about the possibility of studying anc understanding health and disease differently. More than ever before: chronic, rather than communicable, diseases present the greates 1 global impact on health problems; and short-term remedies are being replaced with necessarily long-term management strategies. ${ }^{2}$ Chronic diseases, including heart disease, cancer, and respiratory and metabolic diseases, are estimated to be responsible for $60 \%$ of deaths in the world. $^{3}$ The age of noncommunicable diseases has arrived. ${ }^{4}$ Amongst noncommunicable diseases, the growing prevalence of obesity and its complications (including type 2 diabetes, cardiovascular disease, and nonalcoholic fatty liver disease) are increasingly dominating global ill health and healthcare costs.

At the center of many chronic diseases is inflammation, which is both multifactorial and complex in nature. While inflammation is associated with innate and adaptive immune responses functioning beneficially to protect and heal the body, if it becomes unbalanced it can be deleterious. It is now known that inflammation occurs in different forms (acute and chronic) and that it is driven by different mechanisms of induction, regulation, and resolution. Over the las 1 half-century a shift in the types of inflammation present in humans has occurred-from acute inflammatory responses to injury and infection, to chronic inflammatory states often related to activation of the immune system (such as in rheumatoid arthritis), with the potential mechanisms underpinning the acute inflammatory responses becoming chronic in nature. ${ }^{5}$ Research has demonstrated the role of a number of common risk factors for noncommunicable chronic dis eases, such as genetics, tobacco use, stress, alcohol consumption physical inactivity, adiposity, and diet, in modifying immune responses and ultimately increasing mortality and the financial burden to soci eties. $^{6-8}$ Periodontal diseases and obesity are also risk factors implicated in the onset and progression of chronic inflammation, and its consequences. Host responses are now understood to be governec not by one factor, but by multiple factors. They manifest differently in each individual, and are further determined by the interaction o factors within and around us, thus giving momentum to shifts in med ical approaches toward personalized prediction that takes account of potential modifying factors. Health has become a game of risk playec out by identifying possible negative factors and then implementinc strategies to balance these negative factors with positive factors, ir order to attain or maintain optimal health.

Medical models of chronic disease management suggest that neu paradigms are needed to address the multiplicity of factors implicatec in the pathogenesis of chronic diseases and to cope with the societa demands of the continually increasing incidence of these disorders. ${ }^{9-11}$ The shift to new systems to address the multifactorial nature of chronic diseases is strongly influenced by advances in science and technology that allow greater focus on predictive rather than reactive strategies Increased understanding of the potential modifying factors implicatec in chronic disease onset or progression has highlighted interindividua variability, particularly of those factors influenced by lifestyle. ${ }^{11}$ This knowledge has the potential to enhance opportunities to predict, pre vent, and manage chronic conditions. The personalized medicin $\epsilon$ approach requires patients to play an active part in preventing of managing their own disease; it implies an altered role for the profes sional, who needs to establish, with the patient, a collaborative partnership that is focused on patient participation in the decision making related to therapeutic options. Furthermore, the professional, by acting as a facilitator, can enable and empower the patient to take a central 
position in driving self-management strategies. Collaborative in nature, it has been proposed that patients "will shift from being passengers tc drivers of their health". ${ }^{12}$ Research has demonstrated that interactions between patients and health professionals and the steps of patients toward healthier lifestyle behaviors are more effective if patients are engaged and active in determining their health or disease management Patients become more skilled at self-management, ultimately gaininc self-confidence and self-efficacy. ${ }^{9,11,13}$ There are many diseases, for instance diabetes and asthma, for which this approach has reached $\mathrm{a}$ high level of maturity, due, in part, to the development of tools anc devices that empower the patient to make day-to-day decisions about their own health management. Health promotion, described by the World Health Organization as "the process of enabling people tc increase control over their health and its determinants, and thereby improve their health", through personalized medical approaches is the key to prevention and management of chronic disease. ${ }^{3}$

It is within this context of overall health and chronic disease, with periodontitis and obesity both categorized as noncommunicable chronic inflammatory diseases, that this review investigates and dis. cusses periodontal complications with obesity. Since 2010, periodontitis is cited to be the sixth most prevalent chronic conditior globally; obesity and overweight have now become the norm, affecting $52 \%$ of the world's population. ${ }^{14}$ The understanding of the pathophysiology of obesity has evolved over recent decades to recognize that chronic inflammation, rather than simply mechanical burden, drives its morbidity. ${ }^{15}$ Their common coexistence and potentia synergy for driving health risks suggest that it is time to conside overweight/obesity as a modifying factor in oral health, its assess ment, and management. Cardiovascular disease, one of the mair complications of obesity, is also understood to be driven by the chronic inflammation associated with periodontal diseases. This meta-review summarizes aspects of existing evidence related to the possible impact of obesity on periodontal conditions.

\section{BACKGROUND}

The following sections provide background understanding of the chronic inflammatory diseases periodontitis (a destructive form of periodontal diseases) and overweight/obesity (relating to obesity as a neurochemical disease). A summary of the possible associations between the two diseases is presented as a foundation to permit detailed understanding of the evidence presented in this meta review, of the potential consequences of obesity on periodontitis and associated treatments and its relevance within the context of personalized medicine.

\section{1 | Periodontal diseases}

\subsection{1 | Characteristics and prevalence}

Periodontal diseases are chronic, multiinflammatory diseases of the periodontal tissues, propagated by an inflammatory response to bacterial plaque biofilm. ${ }^{16,17}$ Clinical manifestations of periodonta disease include gingival inflammation (which may lead to periodonta pocket formation as a result of loss of gingival attachment), gingiva recession, alveolar bone loss, tooth mobility, and eventually (if th $\epsilon$ periodontal disease is untreated) tooth loss. ${ }^{18,19}$

In the general population, the prevalence of periodontitis is reported to be $20 \%-50 \% .{ }^{20}$ Most recent estimates in the USA, basec upon Centers for Disease Control and Prevention updated case definitions, suggest $47 \%$ of the adult population suffer from the dis ease..$^{21} \mathrm{~A}$ recent systematic review considering the global burden of severe periodontitis between 1990 and 2010 estimates the prevalence of severe periodontitis at $11.2 \%$, placing it as the 6 th most prevalent global condition. ${ }^{22}$

\subsection{2 | Etiology and pathogenesis}

Despite robust evidence about the infectious nature of periodontitis bacteria have proven to be essential, but not sufficient, to cause dis ease. ${ }^{23}$ Historically, pathogenesis was attributed to specific organisms present in larger proportions, such as Porphyromonas gingivalis Treponema denticola, and Tannerella forsythia, serving to trigger ar inflammatory response. ${ }^{24}$ More recent information emerging from metagenomic approaches highlight the polymicrobial nature of periodontal health and disease, with the latter attributed to a dysbiotic state of the periodontal microbiota. Keystone pathogens, including P. gingivalis, could tip the balance of microbial homeostasis, leading to an altered host-microbe interaction responsible for mediating distinctive inflammatory processes associated with the loss of periodontal tissues. ${ }^{25}$ These local acute inflammatory processes aim initially at eliminating invading organisms. A lack of mechanisms of proresolution are deemed responsible for the transition to a chronic inflam. matory state..$^{5,24,25}$

Toxic products associated with microbial shift, such as lipopolysaccharides within the gingival sulcus, may gain access to the gingival tissue and recruit a local inflammatory response characterized by neutrophils, lymphocytes, and macrophages. ${ }^{26,27}$ Local production of proinflammatory cytokines, such as interleukin-1beta, tumor necrosis factor alpha, and interleukin-6, in order to contain/clear the insult, is, however, associated with connective tissue destruction as a result of host matrix metalloproteinase activation. ${ }^{26,28,29}$

A characteristic inflammatory infiltrate is observed in the periodontium; fibroblasts, junctional epithelial cells, osteoblasts/osteoclasts, macrophages, and polymorphonuclear leukocytes releas $€$ proteinases that are involved in the defence against microbes. ${ }^{29} \mathrm{~A} 1$ the same time, these host proteinases are capable of degrading all known extracellular components of connective tissue and epithelium, including components of both the external basal lamina (basement membrane at the connective tissue-junctional epithelium interface) and the internal basal lamina at the epithelium-tooth interface. These enzymes appear to have the potential to contribute to the lateral and apical proliferation of the junctional epithelium into the connective tissue, as well as to epithelial disintegration through degradation of the internal basal lamina and increases in epithelial permeability. 
Regulation of proteinase activities involves activation of the active enzymes. ${ }^{16,30}$

The actual damage caused by, for example, polymorphonuclear leukocyte proteinases, may be limited in the presence of proteinase inhibitors such as alpha-2 macroglobulin, a1 antitrypsin and tissue inhibitors of metalloproteinases found in the junctiona epithelium and in the gingival crevice. ${ }^{31}$ Also, a limited proteolytic cleavage of matrix molecules and active tissue fragments may, ir turn, regulate cell adhesion, migration, and proliferation ir inflamed tissue. ${ }^{28}$ Cytokines such as interleukin-1, interleukin-6. and tumor necrosis factor alpha, and the arachidonic acid metabolite prostaglandin $E_{2}$, have been strongly associated with the onset and progression of periodontal diseases. ${ }^{32}$ These inflammatory mediators produced within the gingival tissues are alsc secreted into the gingival crevicular fluid by both leukocytes anc activated junctional epithelium cells, and their amounts have beer shown to increase at sites exhibiting periodontal tissue destruction. They induce bone resorption and production of matrix metalloproteinase (collagenase). ${ }^{33,34}$

Periodontal pathogenesis is viewed as multilevel, including clinical, cellular, and subcellular mechanisms. This complex view incorporates an updated concept of modifying factors at every level, servinc to facilitate further understanding of pathogenesis as new evidence emerges. More than ever before, it depicts the complexity of the biological networks that determine health and disease, highlighting the importance of understanding factors that may modify pathways, and ultimately clinical outcomes. ${ }^{25,35}$

\subsection{3 | Risk assessment}

Risk factors for a disease may be environmental, behavioral or biologic, which, if present, directly increase the probability of a diseas $€$ occurring and, if absent or removed, reduce that probability. Evidence exists for the role of bacterial plaque, ${ }^{36}$ cigarette smoking, ${ }^{37,3 \varepsilon}$ diabetes mellitus, ${ }^{39}$ and HIV infection ${ }^{40}$ as risk factors for periodontitis. The term risk indicator is used to describe a probable risk facto that has not yet been confirmed by longitudinal studies. ${ }^{41}$ Risk indicators that may be associated with periodontitis are numerous anc include age, ${ }^{37}$ gender, ${ }^{36}$ ethnicity, ${ }^{42}$ socioeconomic status, ${ }^{43}$ specific subgingival microbiota, ${ }^{44}$ alcohol consumption, ${ }^{45}$ interleukin-1 genotype,${ }^{46,47}$ inadequate physical exercise, ${ }^{48}$ osteoporosis, ${ }^{49}$ metabolic syndrome, obesity, and stress. ${ }^{50,51}$

\section{2 | Overweight/obesity}

\subsection{1 | Characteristics}

Overweight and obesity have become common terms used by the medical and scientific communities, in the press, and at social gatherings, taking on a variety of connotations and characteristics according to the context. Obesity is defined as abnormal or excessive fat accumulation that presents a risk to health. ${ }^{52}$ However, operational definitions use body mass index, in which overweight (body mass index $\geq 25$ and $<30 \mathrm{~kg} / \mathrm{m}^{2}$ ) and obesity (body mass index $\geq 30 \mathrm{~kg} / \mathrm{m}^{2}$, are defined (as body weight in relation to height) to lie within ol above arbitrary standards. ${ }^{52,53}$ Further explanation of body mass index as a measurement tool, and expanded World Health Organiza tion categories, are discussed in the classification of obesity section The body mass index thresholds were set by World Health Organization experts to represent levels of increasing health risk, with the optimal range of $21-23 \mathrm{~kg} / \mathrm{m}^{2}$ recommended for adult Caucasiar populations. ${ }^{54}$

In 1998, the National Institutes of Health reported that "obesity is a complex multifactorial chronic disease", ${ }^{55}$ followed by reference to obesity as a "chronic disease" by the World Health Organizatior in its report from the World Health Organization consultation or obesity in $1999 .{ }^{54}$ Other bodies, including the American Medica Association, World Obesity Federation, and European Associatior for the Study of Obesity, all now recognize and classify obesity as a chronic disease. ${ }^{56}$ While the mechanisms driving overweight anc obesity are simply summarized as "an imbalance between energy intake and expenditure", the causes are more complex, involvinc gene-environment interactions for which the "complex feedback sys tems of both neural and endocrine signaling in response to intake of food", which evolved to respond to undernutrition, no longer protect the individual from overconsumption of food and subsequent weight gain. ${ }^{53}$

Until recently, adipose tissue was believed to be inert tissue that stored fat as a fuel depot. It is now appreciated that adipose tissue is a highly active endocrine organ secreting chemicals that drive inflammation, and that fat can also be deposited outside adipose tissue, in sites such as the liver, thus driving localized inflammation. ${ }^{57}$ Measuring body composition to derive estimates of the total amount of adipose tissue and its distribution is therefore essential for accurately phenotyping individuals and understanding the risks of overweight and obesity.

\subsection{2 | Classification}

The World Health Organization definition of obesity is based or the oldest and most common measure of body composition, body mass index. Body mass index was developed by Adolphe Quatele in 1835 during his attempts to apply statistics to explain socia phenomena. One of these was to classify people's weight relative to the perceived ideal weight for their height. ${ }^{53}$ In the early 1900s, body mass index was used by the insurance industry to demonstrate shortened lifespan, resulting in defined thresholds. ${ }^{58}$ The World Health Organization then adopted the measure, defining a classification system; the current cut-off points are shown ir Table $1 .^{59}$

As more evidence emerges, the World Health Organizatior state that "health risks associated with increasing body mass index are continuous". 59 This has stimulated further breakdown of previous categories into subcategories to accommodate differing definitions of appropriate cut-off values for different ethnic backgrounds. 
TABLE 1 International classification of body mass index (adapted from World Health Organization $2008^{59}$ )

\begin{tabular}{|lll}
\hline & \multicolumn{2}{l}{ Body mass index $\left(\mathrm{kg} / \mathrm{m}^{2}\right)$} \\
\cline { 2 - 3 } Classification & $\begin{array}{l}\text { Principal cut-off } \\
\text { points }\end{array}$ & $\begin{array}{l}\text { Additional cut-off } \\
\text { points }\end{array}$ \\
\hline Underweight & $<18.50$ & $<18.50$ \\
\hline Severe thinness & $<16.00$ & $<16.00$ \\
\hline Moderate thinness & $16.00-16.99$ & $16.00-16.99$ \\
\hline Mild thinness & $17.00-18.49$ & $17.00-18.49$ \\
\hline Normal range & $18.50-24.99$ & $18.50-22.99$ \\
& & $23.00-24.99$ \\
\hline Overweight & $\geq 25.00$ & $\geq 25.00$ \\
\hline Preobese & $25.00-29.99$ & $25.00-27.49$ \\
\hline Obese & & $27.50-29.99$ \\
\hline Obese Class I & $30.00-34.99$ & $\geq 30.00$ \\
\hline Obese Class II & $35.00-39.99$ & $32.50-34.99$ \\
\hline Obese Class III & $\geq 40.00$ & $35.00-37.49$ \\
\hline
\end{tabular}

As other measures of body composition and shape have beer incorporated, corresponding cut-off points have been proposed Recognition of the importance of central or visceral fat in mediatinc the health impact of overweight and obesity ${ }^{60,61}$ has resulted in the World Health Organization adding a threshold related to increasec health risk for waist circumference (a proxy measure of central adipos ity) at $94 \mathrm{~cm}$ for men and $80 \mathrm{~cm}$ for women. ${ }^{59}$ This is a good predictor of visceral and even total body fat. ${ }^{62}$ However, at high body mass index levels, it may be less accurate because of difficulties in obtaining an accurate measure.$^{63}$ It is generally recommended that more thar one measure should be used, whenever possible, to assess body com position and fat distribution, with a selection of specific methods to be chosen based on their relevance to the health risk being assessed. ${ }^{62,64}$

\subsection{3 | Body composition and fat distribution}

While body mass index is frequently used to define overweight anc obesity, it is a poor proxy for body fat. ${ }^{65}$ Body mass index has utility as a simple, objective, and reproducible estimate of fatness in population studies; however, particularly in modestly overweight individu als, body mass index may misclassify health risks. ${ }^{64}$ As nen technologies have become available offering more accurate measure ments of regional fat distribution, the appropriateness of body mass index as a measure of visceral fat in ascertaining risk associated with adiposity has been challenged. ${ }^{66,67}$ Evidence suggests that body mass index has a very high correlation with waist circumference waist: hip ratio, and computed tomography data regarding their asso ciation with clinical outcomes, such as diabetes incidence, and there fore body mass index remains the most commonly used measure of risk associated with central adiposity. ${ }^{68,69}$
In large epidemiological studies, body mass index remains predictive of health risk (cardiovascular disease, cancer, and mortality), but it can be augmented by anthropometric measures of fat distribution. ${ }^{70}$ Body composition can be defined in several ways. Most com. monly, a two-compartment model assumes that the body is composed of fat and nonfat or lean body masses. Fat can be measured directly by dual X-ray absorptiometry, computed tomography: or magnetic resonance imaging, or estimated from measurement of body water by deuterium dilution. Hydrodensitometry or air displacement can allow body volume, and thus density, to measured, and then body fat is estimated using derived equations. ${ }^{71}$ More complex models that do not make assumptions about the hydration of lean tissue can be developed and these may be important in disease states, or where body composition changes in response to treatment, for example, type 2 diabetes. ${ }^{72}$ As knowledge of the health risks associated with being overweight or obese has increasec over the last 100 years, focus on both the fat and lean body mass components of body composition have become increasingly recog. nized as determining the pathological significance of body mass index. Fat levels are dynamic over a lifetime and vary according to age, gender, ethnicity, level of physical activity, and hormonal status. For example, the percentage of body fat increases with age for both men and women, and women generally have a higher percentage of body fat than men, regardless of age, from puberty onward. ${ }^{73}$

More recently, attention has been focused on body fat distribution rather than solely on fat mass. Visceral (intra-abdominal) fat has been shown to be more highly associated with the metabolic syndrome than subcutaneous fat, with the suggested mechanism being linked to differences in adipokine secretion. ${ }^{74}$ Figure 1 depicts areas of fat distribution in the body. There is evidence that proinflammatory adipokines are overproduced with increasing adiposity with their distribution selectively altering the effects on systemic inflammation. ${ }^{75}$

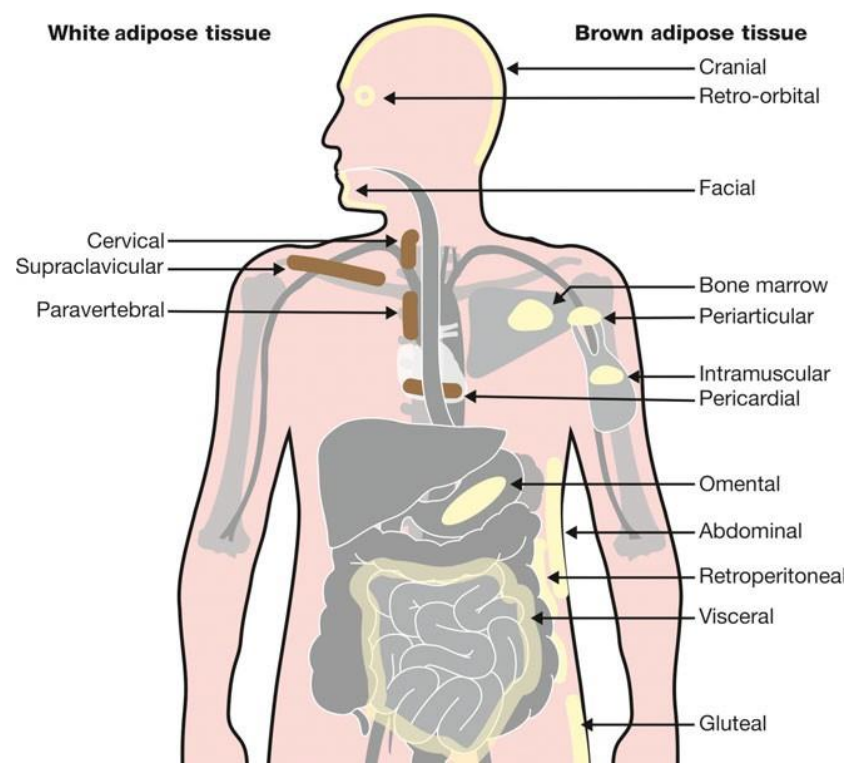

FIGURE 1 Body fat distribution 


\subsubsection{Assessment}

Assessment of overweight/obesity holds challenges similar to thos $€$ of other chronic diseases, including periodontitis. The pursuit to define a measure that is both feasible and relevant to basic research: epidemiological research, clinical research, and most importantly: patient outcomes, is a never-ending journey. ${ }^{76}$ However, over recent years attempts have been made to improve the staging of obesity: so that the severity of its complications is amalgamated with body mass index. The Edmonton Obesity Staging System combines a severity stage for metabolic, "mechanical", and mental health components of obesity and has been shown to improve risk assessment for mortality outcome more accurately than body mass index alone. ${ }^{77,78}$ There are several guidelines on clinical assessment of the obese individual, but in general these do not include measures of inflamma. tion. $^{79}$

\subsection{5 | Prevalence}

The World Health Organization reported overweight/obesity statistics as early as the 1930s and it currently maintains a Global Body Mass Index Database. ${ }^{59}$ In 1997, it reported obesity as an emerging public health problem of epidemic proportions. The worldwide prevalence of obesity has almost tripled since 1975 , with $39 \%$ of adults estimated to be obese, corresponding to 650 million individuals aged over 18 years. ${ }^{52}$ In 2016, 41 million children under the ag€ of 5 years, and 340 million of those aged between 5 and 19 years, were reported as overweight or obese. ${ }^{52}$

\subsection{6 | Health risks associated with obesity}

Obesity has been said to "increase morbidity and mortality through its multiple effects on nearly every human system" ${ }^{80}$ The Worlc Health Organization Global Observatory states that at least 2.8 million people worldwide die each year as a result of overweight of obesity, with mortality rates increasing with higher body mass index. ${ }^{81}$ The disability-adjusted life year is a measure of overall disease burden, expressed as the number of years lost due to ill health. It is estimated that globally, 35.8 million (2.3\%) disability-adjusted life years are caused by overweight or obesity. ${ }^{54}$

There is increasing research evidence demonstrating the association between obesity and increased risk for high blood pressure: cardiovascular disease, osteoarthritis, respiratory disorders, type 2 diabetes, reproductive dysfunction, gallbladder disease, and cancer. In addition, an association of obesity with gastrointestinal, liver: urogenital, skin, and surgical site infections has beer described. ${ }^{80,82,83}$

To achieve optimal health, the median body mass index for an adult population should be $21-23 \mathrm{~kg} / \mathrm{m}^{2}$, while the goal for individuals should be to maintain body mass index between 18.5 and $24.9 \mathrm{~kg} / \mathrm{m}^{2}$. There is increased risk of comorbidities for body mass index $25.0-29.9 \mathrm{~kg} / \mathrm{m}^{2}$, and moderate-to-severe risk of comorbidities for body mass index greater than $30 \mathrm{~kg} / \mathrm{m}^{2} .52$

\subsection{7 | Etiology}

The etiological classification of obesity can be summarized into 5 main categories - genetic, neuroendocrine, drug-induced, sedentary lifestyle, and diet - with many complex mechanisms implicated withir each category. ${ }^{53,84}$ At the simplest level, obesity can be explained as a condition that results when energy intake exceeds energy expenditure, with imbalance provoking changes in the body's fat stores. Twc underlying, currently indisputable, laws of obesity suggest that, first for obesity to develop, energy intake must exceed energy expenditure and, second, obese individuals have a higher level of energy expenditure than lean individuals and therefore require highel energy intake to maintain their higher body mass. ${ }^{85}$

As simple as "energy in versus energy out" may sound, resulting in the stereotypical solution of "eat less and exercise more", the lis of underlying factors that can potentially contribute to energy balance are extensive. The aforementioned etiological classificatior highlights the aspects that may determine energy intake or expendi. ture. For example, genetic, neuroendocrine and drug-induced categories may alter appetite or sensation of satiety. ${ }^{86} \mathrm{~A}$ combination ot all 5 aspects may affect an individual's capacity to maintain ol increase energy expenditure.

A large number of twin, adoption, and family studies have explored the level of heritability of obesity, in other words the frac tion of the population variation in a trait (eg, body mass index) that can be explained by genetic transmission. ${ }^{87}$ Recent studies of individuals with a wide range of body mass index values, together witr information obtained on their parents, siblings, and spouses, sugges that about $25 \%-40 \%$ of the individual differences in body mass ol body fat may depend on genetic factors. However, studies witr identical twins reared separately suggest that the genetic contribu. tion to body mass index may be higher (ie, about $70 \%$ ). ${ }^{88}$ Genomewide association studies have identified nearly 600 polymorphisms that are associated with body weight and altered appetite. Furthermore, specific mutations in key genes, such as those coding for leptin or its receptor, the melanocortin receptor, are known to lead tc early childhood obesity. ${ }^{89,90}$

However, the recent rapid increase in the prevalence of obesity cannot be accounted for simply by genetic change, suggesting that environmental determinants are also important. ${ }^{83}$ Environmenta influences on overweight and obesity are primarily related to fooc intake and physical activity behaviors. In many countries where the population consumes westernized diets there is an overall abun dance of palatable, calorie-dense food. In addition, aggressive anc sophisticated food marketing in the mass media, supermarkets, anc restaurants, and the large portions of food served outside the home promote high calorie consumption. ${ }^{91,92}$

Many of our sociocultural traditions promote overeating and the preferential consumption of high-calorie foods. For many people: even when calorific intake is not above the recommended level, the number of calories expended in physical activity is insufficient to offset consumption. Many people are entrenched in sedentary daily routines consisting of sitting at work, sitting in traffic, and sitting in 
front of a television or a computer monitor for most of their waking hours. ${ }^{83,93}$

Research relating obesity to psychological disorders and emotiona distress is based on community studies and clinical studies of patients seeking treatment. Several recent studies in general populations sug gest a relationship between obesity and emotional problems. ${ }^{94}$ Similarly, overweight people undergoing weight loss treatment may, ir clinical settings, exhibit signs of emotional disturbance. In a review of dieting and depression, there was a high incidence of emotional illness symptoms in outpatients treated for obesity. ${ }^{94}$

\subsection{8 | Pathogenesis}

Adipose tissue, previously viewed as a passive energy store, is now referred to as an endocrine organ in itself. ${ }^{80}$ As adipocytes becom $\epsilon$ larger, they demonstrate altered activity with increased release of proinflammatory mediators and decreased release of antiinflammatory cytokines $^{95,96}$ (Figure 2). Macrophages are recruited through signaling by chemokines (chemokine ligand 2) as a consequence of fat cel expansion and increase during weight gain. The macrophages are primarily located near apoptotic adipocytes. Various mediators synthe sized by the fat cells and resident macrophages then contribute tc local and systemic inflammation through increased production of interleukin-6, tumor necrosis factor alpha, and other proinflammatory cytokines. $^{75,95,97}$

Hence, it is now known that adipose tissue is actively involved ir the regulation of inflammation and immunity associated with the dysregulated or altered release of a variety of proinflammatory anc anti-inflammatory factors (eg, leptin, adiponectin, cytokines, anc chemokines). ${ }^{80}$ Visceral fat (associated with central adiposity) has greater activity than peripheral fat cells regarding the production of endocrine secretions responsible for the effect of fat mass or immune function. ${ }^{69,98}$

The crucial role of adipose tissue in obesity-related systemic inflammation is the active production of hormones and cytokines which acts as the link to many comorbidities of obesity. ${ }^{99}$ Obese fat tissue (enlarged adipocytes compared with lean fat tissue), characterized by macrophage accumulation from the migration of inflammatory monocytes that infiltrate the adipose tissue from the circulation results in secretion of tumor necrosis factor alpha and interleukin- $\epsilon$ by both adipocytes and macrophages. These cytokines (also classi fied as adipo[cyto]kines) regulate systemic inflammation, affecting insulin sensitivity and glucose metabolism (associated with chemokine signaling). Interleukin-6 is associated with decreased insulin sig. naling and induction of fatty acid oxidation, as well as secretion ot C-reactive protein by the liver. Interleukin-6 expression and lipolysis (in the fat cells) are increased by tumor necrosis factor alpha and are known to play a role in insulin resistance. ${ }^{75,97}$ Table 2 lists the myriad of adipokine activity playing a role in the pathogenesis of adipose tissue, and the associated diseases. ${ }^{97}$ There is evidence that some of the anti- or proinflammatory effects of adipokines are active in the innate immune response and that others stimulate an adaptive immune response. ${ }^{100}$

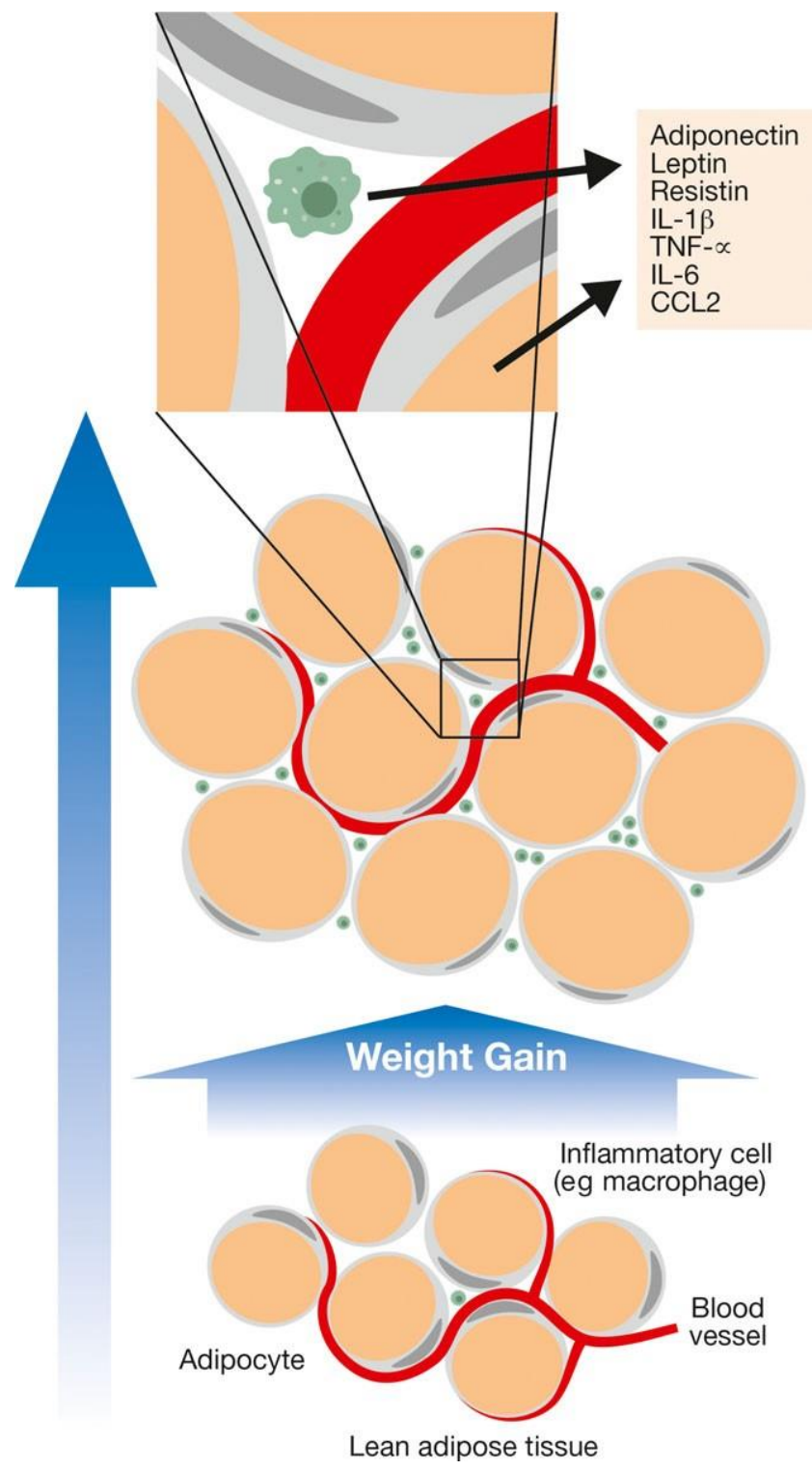

FIGURE 2 Cellular components of lean and obese adipose tissue. CCL2, C-C motif chemokine ligand 2; IL-1b, interleukin-1beta; IL-6, interleukin-6; TNF-a, tumor necrosis factor alpha

\subsection{9 | Risk assessment}

The World Health Organization has identified the importance of addressing common risk factors to reduce the prevalence of noncommunicable diseases, including obesity. ${ }^{4,52,101}$ Linked to the multifactorial nature of overweight and obesity, identified risks include not only those at the individual level, but also those at a societal or environmental level. For health professionals, patient level modifiable risk factors are most relevant; however, these may be included witr other, less modifiable, factors.

The most common risk factors for weight gain or obesity are tobacco cessation, consumption of foods high in saturated and trans fats, salt intake, sugar consumption (especially in sweetened drinks), sedentary lifestyle, as well as excessive alcohol consumption. ${ }^{59}$ In 
TABLE 2 Adipocytokine activity in adipose tissue pathogenesis

\begin{tabular}{|c|c|c|c|c|}
\hline Adipocytokine & $\begin{array}{l}\text { Inflammatory } \\
\text { effect }\end{array}$ & Effects on innate immunity & Effects on adaptive immunity & Associated diseases \\
\hline \multirow[t]{2}{*}{ Adiponectin } & Anti-inflammatory & $\begin{array}{l}\downarrow \text { Endothelial adhesion } \\
\text { molecules } \\
\downarrow \text { NF-kB } \\
\downarrow \text { TNF } \\
\downarrow \text { IL-6 } \\
\downarrow \text { IFN-c } \\
\uparrow \text { IL-10 } \\
\uparrow \text { IL-1RA } \\
\downarrow \text { Phagocytosis }\end{array}$ & $\begin{array}{l}\downarrow \text { B-cell lymphopoiesis } \\
\downarrow \text { T-cell responses }\end{array}$ & $\begin{array}{l}\text { Insulin resistance and type } 2 \text { diabetes } \\
\text { mellitus } \\
\text { Atherosclerosis } \\
\text { Experimentally induced liver disease: } \\
\text { nonalcoholic and alcoholic fatty liver } \\
\text { disease } \\
\text { Cardiac injury } \\
\text { Cancerlnflammatory bowel disease }\end{array}$ \\
\hline & Proinflammatory & $\uparrow$ CXCL8 in presence of LPS & Not determined & Rheumatoid arthritis \\
\hline Leptin & Proinflammatory & $\begin{array}{l}\uparrow \text { TNF } \\
\uparrow \text { IL-6 } \\
\uparrow \text { IL-12 } \\
\uparrow \text { Neutrophil activation } \\
\quad(\text { CD11b) } \\
\uparrow \text { ROS } \\
\uparrow \text { Chemotaxis } \\
\uparrow \text { NK cell function }\end{array}$ & $\begin{array}{l}\uparrow \text { Lymphopoiesis } \\
\uparrow \text { Thymocyte survival } \\
\uparrow \text { T-cell proliferation } \\
\uparrow \text { Th-1 response (IL-2 and IFN- } \\
\text { c) } \\
\downarrow \text { Th-2 response (IL-4) }\end{array}$ & $\begin{array}{l}\text { Insulin resistance } \\
\text { Experimentally induced hepatitis } \\
\text { EAE and antigen-induced arthritis } \\
\text { Experimentally induced colitis (mice) } \\
\text { Asthma } \\
\text { Cancer }\end{array}$ \\
\hline Resistin & Proinflammatory & $\begin{array}{l}\uparrow \mathrm{TNF} \\
\uparrow \mathrm{IL}-1 \mathrm{~b} \\
\uparrow \mathrm{IL}-6 \\
\uparrow \mathrm{IL}-12 \\
\uparrow \mathrm{NF}-\mathrm{jB} \\
\uparrow \text { Endothelial adhesion } \\
\text { molecules (VCAM1 and } \\
\text { ICAM1) }\end{array}$ & Not determined & $\begin{array}{l}\text { Insulin resistance (mice) } \\
\text { Type } 2 \text { diabetes mellitus (mice) } \\
\text { Rheumatoid arthritis } \\
\text { Atherosclerosis } \\
\text { Nonalcoholic fatty liver disease } \\
\text { Chronic kidney disease }\end{array}$ \\
\hline Visfatin & Not determined & $\begin{array}{l}\uparrow \text { IL-6 } \\
\uparrow \text { IL-8 } \\
\downarrow \text { Apoptosis of neutrophils }\end{array}$ & Not determined & $\begin{array}{l}\text { Insulin resistance and type } 2 \text { diabetes } \\
\text { mellitus } \\
\text { Acute lung injury } \\
\text { Sepsis }\end{array}$ \\
\hline
\end{tabular}

$\downarrow$, decrease; $\uparrow$, increase; CXCL, CXC-chemokine ligand; EAE, experimental autoimmune encephalomyelitis; ICAM, intercellular adhesion molecule; IFN-C interferon-c; IL, interleukin; IL-1RA, IL-1 receptor antagonist; LPS, lipopolysaccharide; NF-kB, nuclear factor- kB; NK, natural killer; ROS, reactive oxyger species; Th-1, T-helper 1 cell; Th-2, T-helper 2 cell; TNF, tumor necrosis factor; VCAM, vascular cell adhesion molecule.

Adapted from Tilg and Moschen. ${ }^{95}$

addition, a number of medications are associated with weight gain. These medications include some antidepressants, antiseizure medications, diabetes medications, antipsychotic medications, steroids, anc beta-blockers. ${ }^{102}$ A systematic review of weight gain following smoking cessation has shown that individuals who quit smoking will experience greater weight gain than nonsmokers for a minimum of 1 year. ${ }^{103}$

Sucrose-containing drinks have been identified as a major dietary factor with a greater impact than many other types of food, partly because of the high number of calories in these products. Sugary drinks are easily and quickly consumed, and supply a large numbe of calories but little nutrition or sense of satiety. ${ }^{104}$ Unhealthy diet and sedentary lifestyle are fundamental in assessing risk for overweight and obesity. Accordingly, the impact of these two factors ir the etiology of obesity - energy in vs. energy out - is indisputable and they remain at the center of weight gain. However, awareness of a risk factor does not necessarily make it simple to modify. Socioeconomic and environmental factors known to affect diet anc activity levels have been identified as fundamental elements affecting the risk for overweight and obesity. Education levels and health awareness can influence food purchasing and cooking patterns. Lifestyle factors, such as watching television, eating out, working night shifts, and the distance between home and school or work, are jus a few examples of confounding determinants of diet or physica activity. ${ }^{55,105,106}$ Individuals with irregular and insufficient sleep patterns have been shown to be at a higher risk of weight gain. This is reported to be related to the link between hormone levels/neuroendocrine signaling and appetite/satiety; however, poor dietary habits associated with irregular sleep and work schedules have been implicated as a confounder in this association. ${ }^{84}$

\subsubsection{0 | Therapy for obesity}

Treatment of obesity aims to help the individual maintain a negativ $\epsilon$ energy balance for a sufficiently long duration to utilize storec energy and thus lose weight, and then maintain a lower energy intake and/or increased energy expenditure for long-term mainte nance of weight loss. ${ }^{107}$ Treatment is problematic because there is clear evidence that physiological mechanisms try to maintain body 
weight and restore lost weight, and so-called lifestyle interventions (diet and exercise) result in weight loss of only $2 \%-3 \%$ which is maintained beyond 1-2 years. ${ }^{108}$ More intensive interventions, sucr as those deployed in the Look Action For Health In Diabetes trial, o by using low (or very low) energy diets, can produce both greatel initial weight loss and longer term weight-loss maintenance. ${ }^{109}$ Phar. macotherapies have been developed that can, in conjunction with diet and lifestyle, produce greater and more sustained weight losses of $8 \%-10 \% .{ }^{110}$ However, the development of (laparoscopic) bariatric surgery has shown the greatest impact on weight loss, weight-loss maintenance, and improvement in complications caused by obesity as well as opening research areas on mechanisms for weight loss including gut hormones, microbiota, and bile acids. ${ }^{111-113}$ It is alsc increasingly recognized that the weight loss achieved, and perhaps the mechanisms involved after bariatric surgery, have marked beneficial effects on adipose tissue and systemic inflammation. ${ }^{114}$

\subsubsection{1 | Obesity and periodontal diseases}

Obesity has been shown to modulate the host immune response resulting in increased susceptibility to various infections and exaggerated host immune responses to them. ${ }^{80}$ Adipose tissue (adipocytes) secretes several proinflammatory factors, also implicated in periodontitis, including cytokines (eg, interleukin-6) and chemokines, and car affect T-cell function. ${ }^{80}$ Thirty years ago, experimental evidence sug gested a possible association between obesity and periodontitis. In 1977, Perlstein \& Bissada ${ }^{115}$ published an animal study demonstrating greater alveolar bone resorption in obese compared with nonob ese rats. This is in agreement with a more recent report from Amal et $\mathrm{al}^{116}$ that confirmed dysregulation of immune responses in a periodontitis animal model resulting in increased bone loss. Early evidence suggests that obese individuals are 2-3 times more likely tc suffer from periodontitis independently of traditional risk factors (including age, gender, and cigarette smoking). ${ }^{117-122}$ Several clinica studies investigating the association between obesity and periodontitis have been published in the last 20 years. In addition, a number of systematic reviews have been published during the last 7 years.

Personalized, preventive, and predictive medicine are dependen on robust research evidence to guide clinical assessment, diagnosis and decision-making. Large volumes of published literature are avail able electronically to clinicians. However, the sheer mass of evidence can be overwhelming. Reviews serve to summarize bodies of evidence. Systematic reviews conducted according to a well-formulatec question and protocol to minimize bias in the inclusion of primary studies facilitate the summary of numerous studies, thus allowing clinicians to keep abreast of current literature. ${ }^{123}$ Furthermore, metaanalysis performed as part of systematic reviews combines results tc provide an overall summary estimating the results of multiple stud ies. ${ }^{124}$ In a situation in which multiple systematic reviews have beer published, a meta-review proposes to summarize the content of these multiple systematic reviews, providing an optimal overview o existing evidence and gaps in the research findings. ${ }^{125}$ Assessment of methodological quality is a key part of the process to assist readers in determining the validity and clinical applicability of the findings tc their patients or setting. ${ }^{126}$ Therefore, the aim of this review is tc summarize research evidence to date pertaining to the possible periodontal complications with obesity, using a meta-review approach.

\section{3 | META-REVIEW METHODS}

This meta-review was designed and conducted based upon the Preferred Reporting Items for Systematic reviews and Meta-Analyses statement. $^{127,128}$

\section{1 | Focused question}

A focused question was developed using the population, exposure comparison, outcome criteria $^{129}$ : "What is the association of periodontal diseases and/or periodontal complications and overweight/ obesity in children, adolescents, and adults?"

\subsection{Scope of the review}

All systematic reviews were eligible for inclusion if they reported on research studies conducted in human subjects on the potential association or consequences of overweight/obesity and periodontal dis eases in children, adolescents, or adults and were carried out according to systematic review methodology.

\subsection{Search and screening}

The electronic search strategy was developed using Medical Subject Headings $(\mathrm{MeSH})$ and freetext terms based on overweight/obesity and periodontal/periodontitis, then piloted to confirm its suitability to the focus of the review. In the electronic search, databases were searched to 31 October 2017 using a basic search strategy set a priori and customized as appropriate for each database (Cochrane Library, Ovid National Library of Medicine Database [MEDLINE] Excerpta Medica database [EMBASE], and Literatura Latino-Americana e do Caribe em Ciencias da Saúde [LILACS]). English language was applied as a restriction. Manual searching consisted of checking bibliographic references of review articles. Figure 3 provides an example of the basic search strategy.

Search results were combined in one database and duplicates were removed. Titles and abstracts (when available) of all reports identified through the search were screened by one reviewer (JES) for reviews appearing to meet the inclusion criteria. Full text articles were obtained for potentially relevant reviews, which were then further screened by two reviewers (JES and FD) to confirm their eligibility for inclusion. Narrative reviews or nonrelevant reviews were excluded.

\subsection{Risk of bias assessment and data abstraction}

Assessment of the quality of included systematic reviews was performed according to A MeaSurement Tool to Assess systematic 


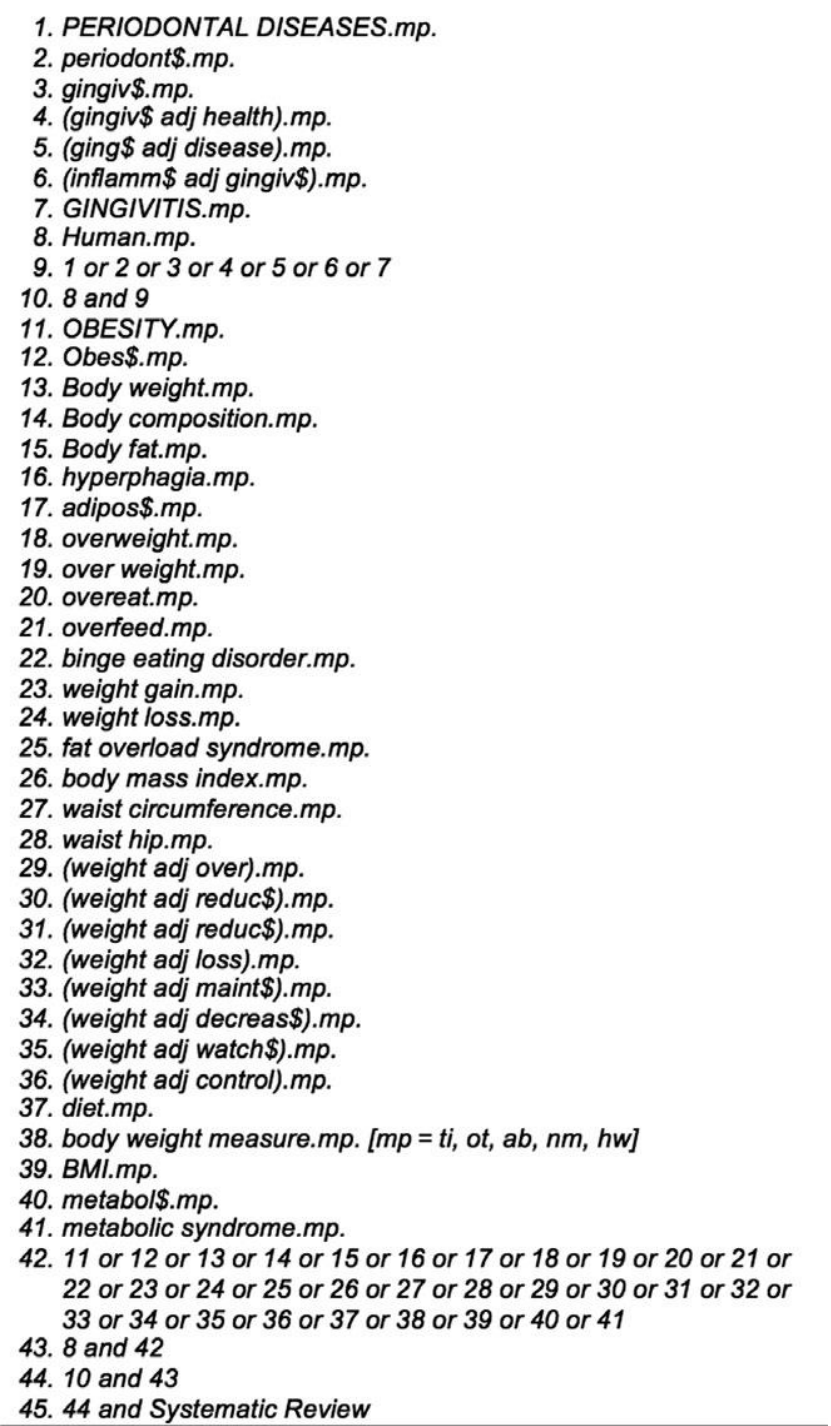

FIGURE 3 Search strategy example for Ovid MEDLINE

Reviews (AMSTAR). ${ }^{123}$ Electronically generated evidence table templates were used for abstracting data from the full text articles (JS) Evidence tables were quality checked for accuracy following data abstraction (FD).

\section{4 | RESULTS}

\subsection{Study selection}

Electronic searches resulted in a total of 486 titles and abstracts: with 9 articles identified through checking of bibliographic lists: resulting in 342 being screened for eligibility following elimination of duplicates. Twenty-eight full text articles were screened for system. atic reviews investigating the association of overweight/obesity anc periodontal diseases. Following exclusion of narrative reviews or nonrelevant reviews, 14 full text systematic reviews were deemec eligible for inclusion in the meta-review. ${ }^{130-143}$ Figure 4 depicts the Preferred Reporting Items for Systematic reviews and Meta-Analyses flow diagram summarizing the search and screening process.
Eleven of the 14 systematic reviews included were publishec between 2015 and 2017 with the remaining 3 being publishec between 2010 and 2014. Six reviews included only cross-sectiona or longitudinal studies, while 8 reviews included only longitudinal o। experimental studies. Two of the 14 reviews reported on children or adolescents only and 2 included adolescents with adult populatior samples. Table 3 provides an overview of the systematic reviews included, Figure 5 depicts the breakdown of study designs, and Fig ure 6 shows the proportion of studies providing evidence of ar association between overweight/obesity and periodontal diseases.

Table 4 summarizes the characteristics and results of the system. atic reviews. Based on A MeaSurement Tool to Assess systematic Reviews (AMSTAR) for the bias assessment of systematic reviews the majority of the included reviews were deemed to be of moderate-to-high quality (Table 5).

The systematic reviews included focused on 4 main themes ot association: overweight/obesity and periodontitis prevalence (some reporting extent and severity); incidence; response to periodonta therapy; and/or periodontal disease biomarkers. The 14 reviews contained some overlap of articles but only 2 included exactly the sam $\epsilon$ articles. Overall, the 14 systematic reviews included a total of 133 unique study publications. Reviews published earlier included a large number of observational studies, while more recent reviews included longitudinal and experimental studies.

\subsection{Overweight/obesity and periodontitis prevalence}

Nine systematic reviews reported on the prevalence or extent anc severity of periodontal complications in overweight or obese individuals. ${ }^{131,132,134,135,136,137,138,139,143}$ Two of these reviews includec studies solely of children and adolescents. ${ }^{135,136}$ Data from these $\subseteq$ reviews show that obese individuals are more likely to have a form of periodontal disease than normal weight individuals, independent of age or gender. In addition, increasing levels of overweigh through obesity are associated with more extensive and severe periodontitis.

\section{3 | Overweight/obese and periodontitis incidence or progression}

Four systematic reviews were identified that report on the incidence of periodontal diseases or progression in overweight/obese or cases of weight gain, with 2 including studies investigating children or adolescents. ${ }^{134,136,141,143}$ These summaries of longitudinal studies shon that overweight/obesity or weight gain increases the risk of onset and/or progression of periodontal diseases.

\section{4 | Overweight/obese and response to periodontal therapy}

Six systematic reviews reported the potential effect of obesity on the clinical response to nonsurgical periodontal 


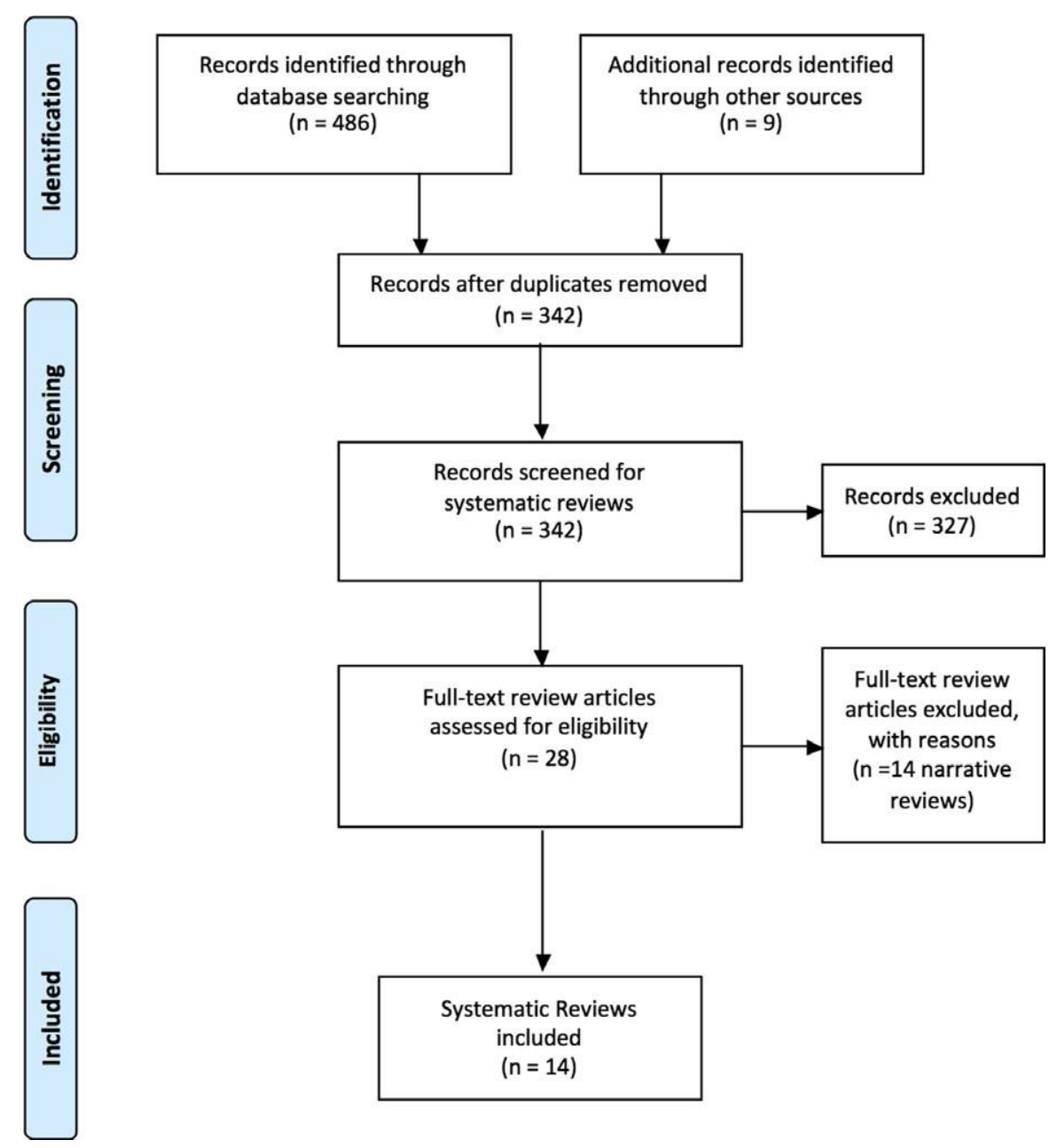

FIGURE 4 Preferred Reporting Items for Systematic Reviews and Meta-Analysis (PRISMA) flow diagram

therapy. ${ }^{131,133,134,137,140,142}$ Two of these reviews included the same 5 studies. Overall, 5 reviews reported inconsistent evidence of differing clinical responses to nonsurgical periodontal therapy in obese individuals. One review reported evidence of obesity as a factor associated with a poorer response to nonsurgical peri odontal therapy. All reviews reported the limited number of studies with small sample size and high levels of heterogeneity in design as restrictions to forming conclusive statements on the effect of obesity on healing following periodontal therapy.

\subsection{Overweight/obesity and biomarkers}

Five systematic reviews reported on prevalence or change in biomarkers associated with inflammation, periodontitis, or obesity. ${ }^{130,131,137,140,142}$ One review reported 2 studies demonstrating increased levels of tumor necrosis factor alpha and decreased levels of adiponectin in obese subjects, with a reduction of tumor necrosis factor alpha and increase in adiponectin following treatment. ${ }^{142}$ However, it was noted that these results were not consistent across studies. The levels of C-reactive protein and proinflammatory cytokines tended to be higher in obese subjects than in nonobese subjects and showed a positive correlation to body mass index. Reduction of cytokine levels following periodontal treatment was reported ir some studies but was inconsistent across studies. Each of the reviews reported inconsistency in results of the levels of serum cytokines in obese individuals and the potential effect of confounding factors.

\subsection{Overweight/obese and periodontal status in children/adolescents}

Two reviews reported on studies of periodontal conditions, such as gingivitis and/or biomarkers of inflammation, in children ol adolescents. ${ }^{135,136}$ These reviews reported poorer gingival health ir obese subjects compared with nonobese subjects with an odds ratic of 1.46 (95\% confidence interval: $1.20-1.77)$ for periodontitis anc obesity, and an odds ratio of 5.41 (95\% Cl: 2.75-10.63) for bleedinc on probing and obesity. Plaque levels were reported to be higher and dietary choices poorer, than in obese and in nonobese children, adolescents; however, associations were independent of these factors. 
TABLE 3 Overview of included systematic reviews

\begin{tabular}{|c|c|c|}
\hline $\begin{array}{l}\text { Systematic review } \\
\text { characteristic }\end{array}$ & $\begin{array}{l}\text { Number of } \\
\text { reviews } \\
(n=14)\end{array}$ & $\begin{array}{l}\text { Author year (reference } \\
\text { number) }\end{array}$ \\
\hline \multicolumn{3}{|l|}{ Publication year } \\
\hline \multirow[t]{3}{*}{$\begin{array}{l}\text { Published prior to and } \\
\text { including } 2014\end{array}$} & \multirow[t]{3}{*}{3} & $\begin{array}{l}\text { Chaffee and Weston } \\
(2010)^{132}\end{array}$ \\
\hline & & Moura-Grec et al (2014) $)^{138}$ \\
\hline & & Suvan et al $(2011)^{143}$ \\
\hline \multirow[t]{9}{*}{ Published 2015-2017 } & \multirow[t]{9}{*}{11} & Akram et al $(2016)^{130,131}$ \\
\hline & & Gerber et al (2016) ${ }^{133}$ \\
\hline & & Keller et al (2015) $)^{134}$ \\
\hline & & Li et al $(2015)^{135}$ \\
\hline & & Martens et al (2017) ${ }^{136}$ \\
\hline & & $\begin{array}{l}\text { Martinez-Herrera et al } \\
(2017)^{137}\end{array}$ \\
\hline & & $\begin{array}{l}\text { Nascimento et al } \\
(2016)^{139,140}\end{array}$ \\
\hline & & Nascimento et al (2015) $)^{141}$ \\
\hline & & $\begin{array}{l}\text { Papageorgiou et al } \\
(2015)^{142}\end{array}$ \\
\hline \multicolumn{3}{|c|}{ Country of corresponding author } \\
\hline Belgium & 1 & Martens et al (2017) ${ }^{136}$ \\
\hline \multirow[t]{3}{*}{ Brazil } & \multirow[t]{3}{*}{4} & Moura-Grec et al (2014) $)^{138}$ \\
\hline & & $\begin{array}{l}\text { Nascimento et al } \\
(2016)^{139,140}\end{array}$ \\
\hline & & Nascimento et al (2015) $)^{141}$ \\
\hline Denmark & 1 & Keller et al $(2015)^{134}$ \\
\hline Germany & 1 & $\begin{array}{l}\text { Papageorgiou et al } \\
(2015)^{142}\end{array}$ \\
\hline Hong Kong & 1 & Li et al $(2015)^{135}$ \\
\hline Malaysia & 2 & Akram et al $(2016)^{130,131}$ \\
\hline Spain & 1 & $\begin{array}{l}\text { Martinez-Herrera et al } \\
(2017)^{137}\end{array}$ \\
\hline Switzerland & 1 & Gerber et al $(2016)^{133}$ \\
\hline UK & 1 & Suvan et al (2011) ${ }^{143}$ \\
\hline USA & 1 & $\begin{array}{l}\text { Chaffee and Weston } \\
(2010)^{132}\end{array}$ \\
\hline
\end{tabular}

\section{Design of included studies}

\begin{tabular}{|c|c|c|}
\hline \multirow[t]{3}{*}{ Cross-sectional only } & \multirow[t]{3}{*}{3} & Li et al $(2015)^{135}$ \\
\hline & & Moura-Grec et al (2014) ${ }^{138}$ \\
\hline & & Nascimento et al (2016) ${ }^{139}$ \\
\hline \multirow[t]{3}{*}{$\begin{array}{l}\text { Cross-sectional and } \\
\text { longitudinal }\end{array}$} & \multirow[t]{3}{*}{3} & $\begin{array}{l}\text { Chaffee and Weston } \\
(2010)^{132}\end{array}$ \\
\hline & & Martens et al (2017) ${ }^{136}$ \\
\hline & & Suvan et al (2011) ${ }^{143}$ \\
\hline \multirow{2}{*}{$\begin{array}{l}\text { Cross-sectional and } \\
\text { experimental }\end{array}$} & \multirow[t]{2}{*}{2} & Akram et al $(2016)^{130}$ \\
\hline & & $\begin{array}{l}\text { Martinez-Herrera et al } \\
(2017)^{137}\end{array}$ \\
\hline Longitudinal only & 1 & Nascimento et al (2015) ${ }^{141}$ \\
\hline
\end{tabular}

TABLE 3 (Continued)

\begin{tabular}{|c|c|c|}
\hline $\begin{array}{l}\text { Systematic review } \\
\text { characteristic }\end{array}$ & $\begin{array}{l}\text { Number of } \\
\text { reviews } \\
(n=14)\end{array}$ & $\begin{array}{l}\text { Author year (reference } \\
\text { number) }\end{array}$ \\
\hline $\begin{array}{l}\text { Longitudinal and } \\
\text { experimental }\end{array}$ & 1 & Keller et al $(2015)^{134}$ \\
\hline \multirow[t]{4}{*}{ Experimental only } & \multirow[t]{4}{*}{4} & Akram et al $(2016)^{131}$ \\
\hline & & Gerber et al $(2016)^{133}$ \\
\hline & & Nascimento et al $(2016)^{140}$ \\
\hline & & Papageorgiou et al (2015) ${ }^{142}$ \\
\hline \multicolumn{3}{|l|}{ Population sample } \\
\hline \multirow[t]{9}{*}{ Adult only } & \multirow[t]{9}{*}{10} & Akram et al (2016) ${ }^{131}$ \\
\hline & & $\begin{array}{l}\text { Chaffee and Weston } \\
(2010)^{132}\end{array}$ \\
\hline & & Gerber et al $(2016)^{133}$ \\
\hline & & Keller et al $(2015)^{134}$ \\
\hline & & $\begin{array}{l}\text { Martinez-Herrera et al } \\
(2017)^{137}\end{array}$ \\
\hline & & $\begin{array}{l}\text { Nascimento et al } \\
(2016)^{139,140}\end{array}$ \\
\hline & & Nascimento et al $(2015)^{141}$ \\
\hline & & Papageorgiou et al $(2015)^{142}$ \\
\hline & & Suvan et al (2011) ${ }^{143}$ \\
\hline \multirow[t]{2}{*}{ Children/adolescent } & \multirow[t]{2}{*}{2} & Li et al $(2015)^{135}$ \\
\hline & & Martens et al (2017) ${ }^{136}$ \\
\hline \multirow[t]{2}{*}{ Adult and adolescent } & \multirow[t]{2}{*}{2} & Akram et al (2016) \\
\hline & & Moura-Grec et al (2014) $)^{138}$ \\
\hline \multicolumn{3}{|c|}{ Interventions treatment response studies } \\
\hline \multirow[t]{4}{*}{ Nonsurgical only } & \multirow[t]{4}{*}{4} & Akram et al (2016) ${ }^{131}$ \\
\hline & & Keller et al (2015) ${ }^{134}$ \\
\hline & & $\begin{array}{l}\text { Martinez-Herrera et al } \\
(2017)^{137}\end{array}$ \\
\hline & & Nascimento (2016) ${ }^{140}$ \\
\hline \multirow{2}{*}{$\begin{array}{l}\text { Included adjuncts to } \\
\text { nonsurgical }\end{array}$} & \multirow[t]{2}{*}{2} & Gerber et al $(2016)^{133}$ \\
\hline & & Papageorgiou et al (2015) ${ }^{142}$ \\
\hline \multicolumn{3}{|l|}{ Meta-analysis performed } \\
\hline \multirow{9}{*}{$\begin{array}{l}\text { Meta-analysis of some } \\
\text { studies }\end{array}$} & \multirow[t]{9}{*}{11} & Akram et al $(2016)^{130,131}$ \\
\hline & & $\begin{array}{l}\text { Chaffee and Weston } \\
(2010)^{132}\end{array}$ \\
\hline & & Li et al $(2015)^{135}$ \\
\hline & & Martens et al (2017) $)^{136}$ \\
\hline & & Moura-Grec et al (2014) $)^{138}$ \\
\hline & & $\begin{array}{l}\text { Nascimento et al } \\
(2016)^{139,140}\end{array}$ \\
\hline & & Nascimento et al (2015) ${ }^{141}$ \\
\hline & & Papageorgiou et al (2015) ${ }^{142}$ \\
\hline & & Suvan et al (2011) ${ }^{143}$ \\
\hline \multirow[t]{3}{*}{ No meta-analysis } & \multirow[t]{3}{*}{3} & Gerber et al (2016) ${ }^{133}$ \\
\hline & & Keller et al (2015) ${ }^{134}$ \\
\hline & & $\begin{array}{l}\text { Martinez-Herrera et al } \\
(2017)^{137}\end{array}$ \\
\hline
\end{tabular}




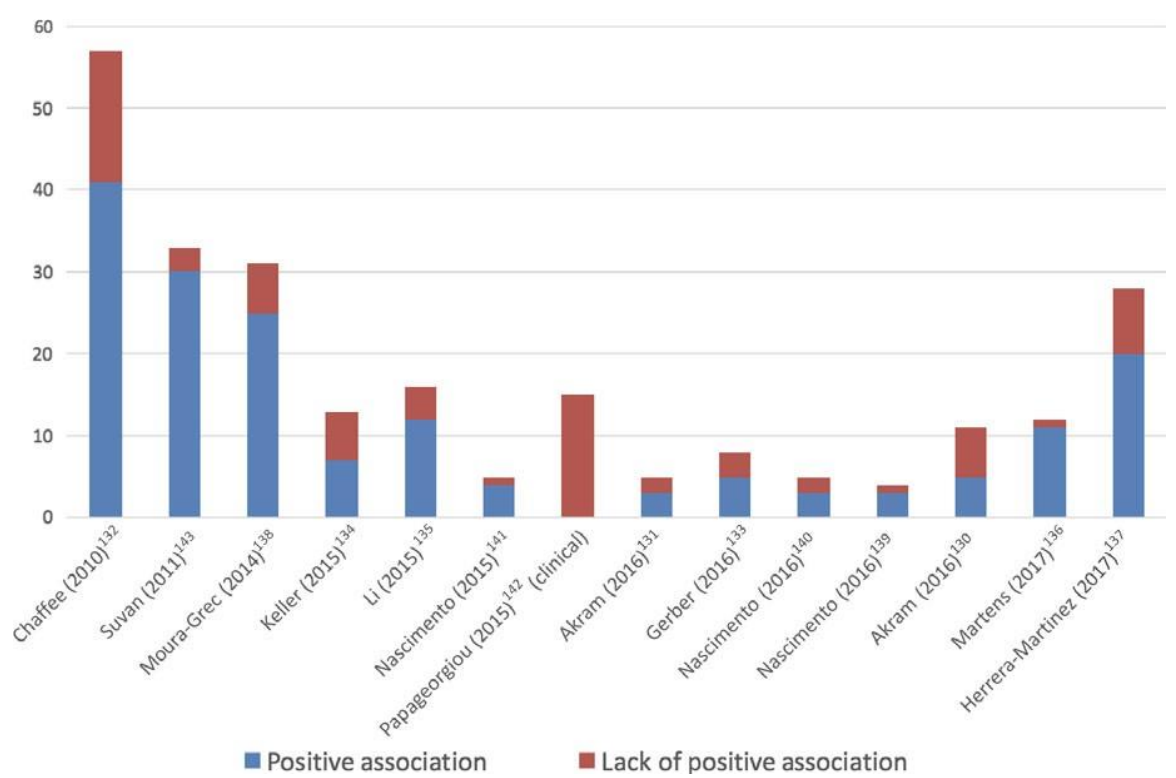

FIGURE 5 Summary of frequency of study designs in systematic reviews

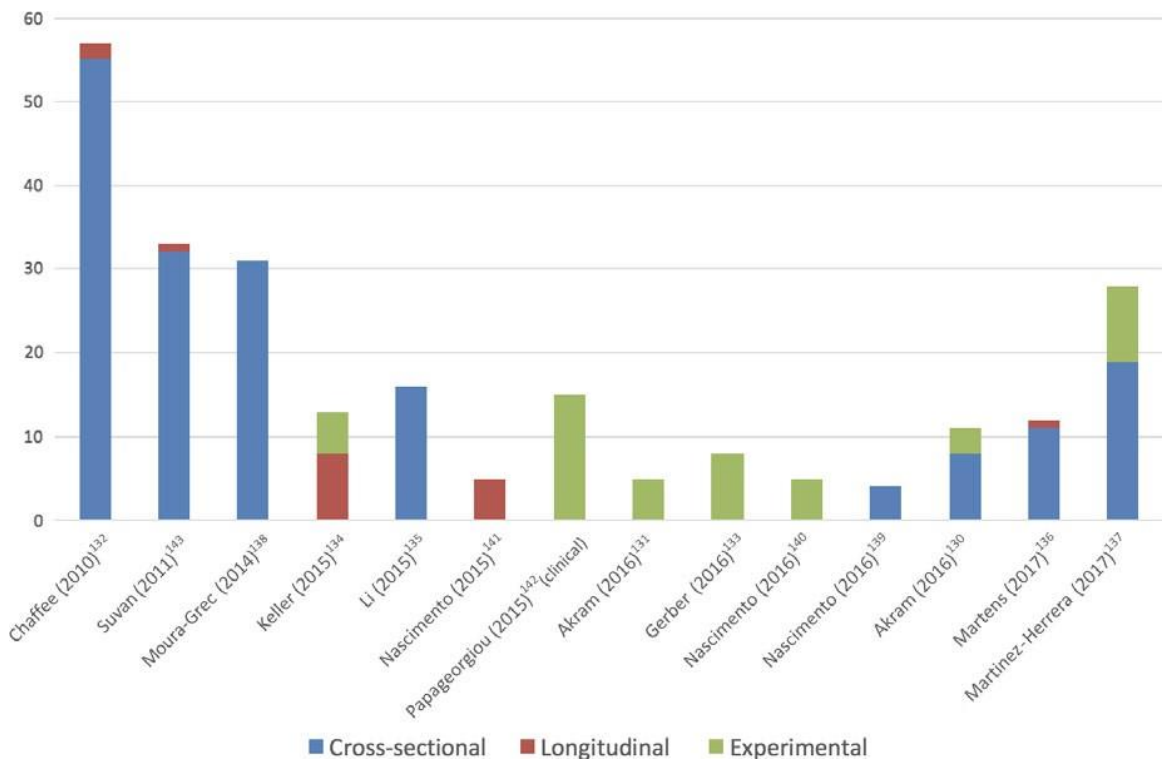

FIGURE 6 Overview of frequency of studies supporting an association between overweight/obesity and periodontal diseases

\section{5 | DISCUSSION}

Overall, the findings of this meta-review indicate a positive association between obesity and periodontal diseases in children, adoles cents, and adults. Although a large body of evidence for the potentially negative impact of overweight/obesity on periodonta diseases exists, the magnitude and mechanisms of this association still require further clarification.

With all 14 reviews published within a time frame of 7 years, it was anticipated that there would be significant overlap in the articles included: however, this was not the case. As early observational evidence confirming a positive association between prevalence and incidence, more recent studies have focused on experimental studies or mechanistic aspects, advancing the investigative process of establishing whether or not obesity is a risk factor or risk indicator for periodontal diseases.

Increased odds of having periodontitis if an individual is overweight or obese have recently been confirmed. ${ }^{144-146}$ Studies have reported a dose-response relationship for the association between obesity and periodontitis. For example, a cross-sectional investigation in Brazil, reported in 2012, revealed a positive relationship between the prevalence/presence of periodontitis and degree of obesity by comparing periodontal status based on full mouth measurements in women grouped as nonobese, overweight, and World 
TABLE 4 Characteristics of included systematic reviews in chronological order of publication

\begin{tabular}{|c|c|c|c|c|c|}
\hline $\begin{array}{l}\text { Publication (First author, year, } \\
\text { reference number, Country, } \\
\text { Article title) }\end{array}$ & Scope of the review & $\begin{array}{l}\text { Overweight/obesity case } \\
\text { definitions or related } \\
\text { parameters }\end{array}$ & $\begin{array}{l}\text { PD case definition or related } \\
\text { parameters }\end{array}$ & Results & Author conclusions \\
\hline $\begin{array}{l}\text { Chaffee }(2010)^{132} \\
\text { USA } \\
\text { Association between chronic } \\
\text { periodontal disease and } \\
\text { obesity: A systematic review } \\
\text { and meta-analysis }\end{array}$ & $\begin{array}{l}\text { Designs: All study designs other } \\
\text { than case series. } \\
\text { Human studies. } \\
\text { Sample: Adults. } \\
\text { Search: MEDLINE, SCOPUS, } \\
\text { BIOSIS, LILACS, Cochrane, } \\
\text { Brazilian Bibliography of } \\
\text { Dentistry databases. } \\
\text { Language: English and Spanish. } \\
\text { Year: Up to and including July } \\
2010 . \\
\text { Aim: To systematically compile } \\
\text { evidence of an obesity- } \\
\text { periodontal disease relationship } \\
\text { from epidemiologic studies, and } \\
\text { to derive a quantitative } \\
\text { summary of the association } \\
\text { between these disease states }\end{array}$ & $\begin{array}{l}\text { Five different definitions/ } \\
\text { criteria/BMI cut-off points } \\
\text { reported to categorize } \\
\text { overweight/obesity. } \\
\text { Measures reported included } \\
\text { BMI, WHR }\end{array}$ & $\begin{array}{l}18 \text { different definitions/criteria } \\
\text { reported to categorize as } \\
\text { periodontal disease }\end{array}$ & $\begin{array}{l}\text { Number of included studies: } 70 \\
\text { studies of } 57 \text { study } \\
\text { populations, no experimental } \\
\text { studies, } 2 \text { studies prospective. } \\
\text { Meta-analysis: } 28 \text { studies. } \\
41 \text { studies showing a positive } \\
\text { association. } \\
\text { Fixed effect summary association } \\
\text { of prevalence of periodontitis } \\
\text { and obesity: OR = } 1.35 \text { ( } 95 \% \\
\text { Cl: } 1.23-1.47) \text {. } \\
\text { Greater mean clinical attachment } \\
\text { loss among individuals with } \\
\text { obesity. } \\
\text { Higher mean BMI among } \\
\text { periodontal patients. } \\
\text { Trend of increasing odds of PD } \\
\text { prevalence with increasing BMI } \\
\text { Many potential confounders } \\
\text { among studies }\end{array}$ & $\begin{array}{l}\text { This positive association } \\
\text { was consistent and } \\
\text { coherent with a } \\
\text { biologically plausible role } \\
\text { for obesity in the } \\
\text { development of } \\
\text { periodontal disease. } \\
\text { However, with few quality } \\
\text { longitudinal studies, there } \\
\text { is an inability to } \\
\text { distinguish the temporal } \\
\text { order of events, thus } \\
\text { limiting the evidence that } \\
\text { obesity is a risk factor for } \\
\text { PD or that periodontitis } \\
\text { might increase the risk of } \\
\text { weight gain. In clinical } \\
\text { practice, a higher } \\
\text { prevalence of PD should } \\
\text { be expected among obese } \\
\text { adults }\end{array}$ \\
\hline $\begin{array}{l}\text { Suvan }(2011)^{143} \\
\text { UK } \\
\text { Association between } \\
\text { overweight/obesity and } \\
\text { periodontitis in adults: A } \\
\text { systematic review }\end{array}$ & $\begin{array}{l}\text { Designs: All study designs other } \\
\text { than case series. } \\
\text { Human studies. } \\
\text { Sample: Adults. } \\
\text { Search: MEDLINE, EMBASE, } \\
\text { LILACS, SIGLE. } \\
\text { Language: No restrictions. } \\
\text { Year: Up to and including } \\
\text { December } 2009 \text {. } \\
\text { Aim: To provide a systematic } \\
\text { review of the evidence to date } \\
\text { investigating the association } \\
\text { between overweight/obesity } \\
\text { and periodontitis }\end{array}$ & $\begin{array}{l}\text { Eight different definitions/ } \\
\text { criteria/BMlcut-off points } \\
\text { reported to categorize } \\
\text { overweight/obesity. } \\
\text { Measures reported included } \\
\text { BMI, WHR, WC, body fat } \\
\text { percentage }\end{array}$ & $\begin{array}{l}16 \text { different definitions/criteria } \\
\text { reported to categorize as PD }\end{array}$ & $\begin{array}{l}\text { No. of included studies: } 33 \text { (1 } \\
\text { longitudinal, } 32 \text { observational). } \\
\text { Meta-analysis: Overweight/ } \\
\text { periodontitis: } 7 \text { studies. } \\
\text { Obese/periodontitis: } 12 \text { studies. } \\
\text { Overweight/obese/periodontitis: } \\
13 \text { studies. } \\
\text { Fixed-effect summary of } \\
\text { prevalence of periodontitis and } \\
\text { WHO BMl obese: OR = } 1.81 \\
\text { (95\% Cl: } 1.42-2.30), \text { WHO BMI } \\
\text { overweight/obese: OR = } 1.27 \\
\text { (95\% Cl: } 1.06-1.51) \text {, and } \\
\text { obese/overweight combined } \\
\text { OR = } 2.13 \text { (95\% Cl: } 1.40-3.26) \text {. } \\
\text { Heterogeneity among studies } \\
\text { noted }\end{array}$ & $\begin{array}{l}\text { These results support an } \\
\text { association between BMI } \\
\text { representing overweight } \\
\text { and obesity and } \\
\text { periodontitis although the } \\
\text { magnitude is unclear. } \\
\text { Additional prospective } \\
\text { studies to further quantify } \\
\text { or understand the } \\
\text { mechanisms of this } \\
\text { association are merited. } \\
\text { There is insufficient } \\
\text { evidence to provide } \\
\text { guidelines to clinicians on } \\
\text { the clinical management } \\
\text { of periodontitis in } \\
\text { overweight and obese } \\
\text { individuals }\end{array}$ \\
\hline
\end{tabular}




\begin{tabular}{|c|c|c|c|c|c|}
\hline $\begin{array}{l}\text { Publication (First author, year, } \\
\text { reference number, Country, } \\
\text { Article title) }\end{array}$ & Scope of the review & $\begin{array}{l}\text { Overweight/obesity case } \\
\text { definitions or related } \\
\text { parameters }\end{array}$ & $\begin{array}{l}\text { PD case definition or related } \\
\text { parameters }\end{array}$ & Results & Author conclusions \\
\hline $\begin{array}{l}\text { Moura-Grec }(2014)^{138} \\
\text { Brazil } \\
\text { Obesity and periodontitis: } \\
\text { systematic review and meta- } \\
\text { analysis }\end{array}$ & $\begin{array}{l}\text { Designs: All study designs other } \\
\text { than case series. } \\
\text { Sample: Humans aged } 15 \text { y } \\
\text { and older. } \\
\text { Search: MEDLINE, EMBASE, } \\
\text { LILACS, Cochrane. } \\
\text { Language: English, Spanish, and } \\
\text { Portuguese. } \\
\text { Year: No restriction up to and } \\
\text { including December } 2010 . \\
\text { Aim: To conduct a systematic } \\
\text { review of the studies on the } \\
\text { association between obesity } \\
\text { and periodontitis }\end{array}$ & $\begin{array}{l}\text { Eight different definitions/ } \\
\text { criteria/BMIcut-off points } \\
\text { reported to categorize } \\
\text { overweight/obesity. } \\
\text { Measures reported included } \\
\text { BMI and, WC }\end{array}$ & $\begin{array}{l}16 \text { different definitions/criteria } \\
\text { reported to categorize as PD }\end{array}$ & $\begin{array}{l}\text { No. of included studies: } 31 \text { (all } \\
\text { cross-sectional). } \\
\text { Meta-analysis: } 22 \text { studies. } \\
\text { Positive association of obesity } \\
\text { as a risk factor for } \\
\text { periodontitis in } 25 \text { studies, } 6 \\
\text { did not show a positive } \\
\text { association. } \\
\text { Compared with normal weight, } \\
\text { overweight and obese showed } \\
\text { increased odds or periodontal } \\
\text { disease OR }=1.30 \text { ( } 95 \% \mathrm{Cl} \text { : } \\
1.25-1.35)\end{array}$ & $\begin{array}{l}\text { Obesity was associated } \\
\text { with periodontitis; } \\
\text { however, the risk factors } \\
\text { that aggravate these } \\
\text { diseases should be better } \\
\text { clarified to elucidate the } \\
\text { direction of this } \\
\text { association. Working with } \\
\text { paired samples and } \\
\text { avoiding confusion factors } \\
\text { may contribute to } \\
\text { homogeneity between the } \\
\text { studies }\end{array}$ \\
\hline $\begin{array}{l}\text { Keller }(2015)^{134} \\
\text { Denmark } \\
\text { Association between } \\
\text { periodontal disease and } \\
\text { overweight and obesity: A } \\
\text { systematic review }\end{array}$ & $\begin{array}{l}\text { Designs: Longitudinal (cohort) } \\
\text { and experimental studies. } \\
\text { Sample: Children, adolescents, } \\
\text { adults. } \\
\text { Search: MEDLINE, Web of } \\
\text { Knowledge. } \\
\text { Language: Not reported. } \\
\text { Year: No restriction up to and } \\
\text { including June 2014. } \\
\text { Aim: To examine the time- } \\
\text { dependent association } \\
\text { between obesity and } \\
\text { periodontitis in the general } \\
\text { population }\end{array}$ & $\begin{array}{l}\text { Overweight/obesity definitions/ } \\
\text { cut-off points not reported. } \\
\text { Measures reported include } \\
\text { BMI and WC }\end{array}$ & $\begin{array}{l}\text { Seven different periodontal } \\
\text { outcomes reported; PD and } \\
\text { CAL were the most common } \\
\text { outcomes. } \\
\text { All intervention studies } \\
\text { reported on nonsurgical } \\
\text { periodontal therapy }\end{array}$ & $\begin{array}{l}\text { No. of included studies: } 8 \\
\text { longitudinal. } \\
5 \text { experimental. } \\
\text { Meta-analysis: None. } \\
5 / 8 \text { longitudinal studies: } \\
\text { positive association between } \\
\text { degree of overweight/obesity } \\
\text { and development of } \\
\text { periodontitis. } \\
2 / 5 \text { intervention studies } \\
\text { reported better response to } \\
\text { therapy in lean patients } \\
\text { compared with obese patients. } \\
3 / 5 \text { intervention studies did } \\
\text { not report differences in } \\
\text { response to therapy. } \\
1 / 5 \text { intervention study showed } \\
\text { increased response in bariatric } \\
\text { surgery patients compared } \\
\text { with controls }\end{array}$ & $\begin{array}{l}\text { This systematic review } \\
\text { suggests that overweight, } \\
\text { obesity, weight gain, and } \\
\text { increased WC may be risk } \\
\text { factors for development } \\
\text { of periodontitis or } \\
\text { worsening of periodontal } \\
\text { measures }\end{array}$ \\
\hline
\end{tabular}


TABLE 4 (Continued)

Publication (First author, year,

reference number, Country,

Article title)

Li (2015) ${ }^{135}$

Hong Kong Anthropometric

measurements and

periodontal diseases in

children and adolescents: a

systematic review and meta-

analysis

\section{Scope of the review}

Design: Observational or

longitudinal studies.

Sample: Children, adolescents.

Search: MEDLINE, Web of

Knowledge, Cochrane,

ProQuest, British Nursing

Index, ComDisDome, Gender

Watch

Language: English.

Year: No restriction up to and

including December 2014

Aim: To identify and

summarize evidence of the

association between

anthropometric measurements

and periodontal status in

children and adolescents
Overweight/obesity case

definitions or related

BMI standard categories

parameters

Results

Various periodontal outcomes

mployed including gingival

bleeding, loss of attachment,

PI, probing pocket depth, CPI,

$\mathrm{Gl}$, and calculus

Design: Longitudinal studies.

Sample: Adults.

Search: MEDLINE, EMBASE,

Web of Knowledge, SCOPUS

Language: No language

restrictions.

Year: No restriction up to and

including February 2015.

Aim: To conduct a systematic

review assessing the effects of

weight gain on the incidence

of perioBontitis in adults
WHO BMI category cutpoints in 4 definitions of PD

all studies. $\quad 4$ definitions of disease

WC reported in 2 studies with progression

differing cut-off points
Number of included studies: 16 .

All cross-sectional; 1 on

preschool children, 9 on

children with mixed dentition,

and 6 on adolescents.

Meta-analysis: 3 studies.

3 studies: obese compared

with nonobese; plaque and

obesity $\mathrm{OR}=4.75(95 \% \mathrm{Cl}$ :

2.42-9.34) $(P<.001)$

3 studies: BOP and obesity

$\mathrm{OR}=5.41(95 \% \mathrm{Cl}: 2.75$ -

10.63) $(P<.001)$.

2 studies: probing depth

$>4 \mathrm{~mm}$ and obesity no

association.

2 studies: subgingival calculus

and obesity $\mathrm{OR}=3.07(95 \%$

$\mathrm{Cl}: 1.10-8.62)(\mathrm{P}<.001)$

No. of included studies: 5 .

All prospective.

Meta-analysis: 5 studies.

Patients in overweight/obese

category had higher risk for

developing periodontitis than

those in BMI nonobese

category.

Overweight RR $=1.13(95 \%$

Cl: 1.06-1.20).

Obese RR $=1.33(95 \% \mathrm{Cl}$ :

1.21-1.47)
Author conclusions

ity is associated with

some signs of PD in

children and adolescents.

Further studies with a

comprehensive

prospective cohort design

and more potential

variables are

recommended

A clear positive association between weight gain and new cases of periodontitis was found. However, these results originated from limited evidence.

Therefore, more studies

with longitudinal

prospective design are needed 


\section{TABLE 4 (Continued)}

Publication (First author, year,

reference number, Country,

Article title)

Papageorgiou (2015) ${ }^{142}$

Germany

Effect of overweight/obesity

on response to periodontal

treatment: Systematic review

and a meta-analysis
Overweight/obesity case

definitions or related

parameters

Scope of the review

Design: Randomized and

nonrandomized experimental

studies.

Sample: Adults.

Search: Databases not

reported

Language: No restrictions.

Year: No restriction up to and including July 2013.

Aim: To investigate whether the

response to periodontal

treatment differs among obese,

overweight, or nonobese

patients
PD case definition or related

parameters

WHO categories of BMI.

Overweight/obese grouped

together in some studies or analyses and separated in

others

Interventions included:

- supra-gingival debridement

(1/15).

- nonsurgical periodonta therapy (8/15)

- nonsurgical therapy plus antibiotics (5/15).

- nonsurgical therapy plus surgical therapy $(1 / 15)$
Results

No. of included studies: 15

4 RCTs and 11 non-RCTs.

Meta-analysis: 8 studies (with

subgroup analyses in

nondiabetic or diabetic

population samples) analyzing

mean difference from baseline.

No statistically significant

differences were found in PPD

or CAL between overweight/

obese and nonobese groups,

between baseline and post

therapy. All therapies were

grouped together in the meta-

analysis.

Significant differences in

inflammatory and metabolic

parameters were based on 1

study in which the level of

TNF-a was found to be higher

in overweight/obese individuals

before treatment and

demonstrated greater reduction

after treatment compared with

nonobese individuals. Mean

difference: $-1.57(95 \% \mathrm{Cl}$

-2.61 to -0.53$) \mathrm{pg} / \mathrm{mL}$.
Author conclusions

Whereas no difference was

found in clinical

periodontal parameters,

significant differences in

nflammatory or metabolic

parameters were found

between overweight/

obese and nonobese

patients, but existing

evidence is weak 
TABLE 4 (Continued)

Publication (First author, year,

reference number, Country,

Article title)

Akram (2016) $)^{131}$

Malaysia

Efficacy of nonsurgical

periodontal therapy in the

management of chronic

periodontitis among obese

and nonobese patients: a

systematic review and meta-

analysis
Overweight/obesity case definitions or related

Scope of the review

Design: Intervention studies.

Sample: Adults.

Search: MEDLINE, EMBASE,

Cochrane, SCOPUS, Google

Scholar, Web of Knowledge.

Language: Not reported.

Year: From 1977 up to and

including December 2014

Aim: To evaluate the efficacy

of NSPTin the management of

$\mathrm{CP}$ among obese and

nonobese patients

WHO BMI cut-off points
PD case definition or related

parameters

Results wereused for defining obesity.

Nonsurgical therapy without adjunctive therapies.

Test group: obese.

Control group: nonobese.

Some studies included smokers and others excluded smokers

Number of included studies: 5 .

2/5 studies showed statistically

significant differences in

clinical parameters, with

nonobese subjects

demonstrating better

periodontal condition following

therapy.

Meta-analysis: 3

Only $3 / 5$ studies (2 reporting

no difference in clinical

parameters between obese and

nonobese subjects after

treatment and one reporting

statistically significant

difference) reported similar

clinical parameters and were

combined in meta-analysis;

however, heterogeneity was

high.

No statistically significant

differences were reported in

clinical parameters (PPD and

$\mathrm{CAL}$ ) between obese and

nonobese subjects in the

overall mean reported in the

meta-analysis.

Biomarkers investigated were

IL-6, IL-1b, IFN-c, TNF-a, CRP

leptin, and adiponectin: results were variable and inconclusive
Author conclusions

It remains unclear whether NSPT has a significantly higher impact on the

clinical periodontal

outcomes in obese patients than in nonobese

periodontitis, given that

the number of selected

studies was relatively low

and the reported findings

were inconsistent 
TABLE 4 (Continued)

Publication (First author, year,

reference number, Country,

Article title)

Akram (2016) ${ }^{130}$

Malaysia

Cytokine profile in chronic

periodontitis patients with

and without obesity: A

systematic review and meta-

analysis
Overweight/obesity case

definitions or related

Scope of the review

Design: Clinical trials, cross-

sectional, observational studies.

Sample: Adults, adolescents

Search: MEDLINE, EMBASE,

Science Direct SCOPUS, Web

of Knowledge.

Language: Not reported.

Year: From 1977 up to and

including May 2016.

Aim: To systematically review

the gingival crevicular fluid

cytokine profile in chronic

periodontitis patients with and

without obesity

the review
PD case definition or related

parameters Results

$\begin{array}{lll}\text { Results } & \text { Author conclusions }\end{array}$

Cut-off points used to define

16 different definitions/criteria

were reported to categorize as

PD

Number of included studies: 11

8 cross-sectional and 3

studies were not reported in

Four studies required $>30 \%$ of

intervention studies (non-RCT).

Meta-analysis: separate for

sites to be affected.

All samples from GCF

each of the following

cytokines: resistin, adiponectin

TNF-a, resistin, leptin, IL-6, IL-

8, IL-1b.

Obese subjects versus

nonobese subjects with

chronic periodontitis:

- TNF-a: significant mean

difference $(P=.004)$.

- IL-6: no mean difference

$(P=.903)$.

- resistin: significantly higher resistin levels in obese subjects $(P=.02)$.

- adiponectin: no mean

difference $(P=.23)$.

- leptin: no mean difference

$$
(\mathrm{P}=.87) \text {. }
$$

- IL-8: no mean difference $(\mathrm{P}=.22)$.

- IL-1b: significant mean

difference $(P<.001)$ of localized

periodontal inflammation

may have greater

influence on the levels of

proinflammatory

biomarkers in GCF

compared with systemic

besity. Whether or not

patients with chronic

periodontitis and obesity

have elevated

proinflammatory levels of

biomarkers in GCF

compared with nonobese

individuals remains a

matter of debate 
Publication (First author, year, reference number, Country,

Article title)

Gerber (2016) ${ }^{133}$

Switzerland

Influence of obesity on the

outcome of nonsurgical

periodontal therapy - a

systematic review
Scope of the review

Design: Intervention studies.

Sample: Adults.

Search: SCOPUS, MEDLINE,

Cochrane, CINAHL, BioSIS,

Web of Science.

Language: Restricted to English and German.

Year: No restriction up to and including January 2016

Aim: To study the hypothesis

whether the clinical outcome,

in terms of pocket depth

reduction, after nonsurgical

periodontal therapy in

nonobese individuals, is better

than in obese individuals
Overweight/obesity case

definitions or related

parameters

WHO BMI cut-off points used to define obesity

parameters

$\begin{array}{ll} & \text { including oral hygiene } \\ \text { instruction }\end{array}$

PD case definition or related

Results

Number of included studies: 8 .

All interventional.

Meta-analysis: None.

$3 / 8$ studies failed to show

influence of obesity on pocket

depth reduction after

nonsurgical therapy.

$5 / 8$ studies showed a clear

negative effect of obesity on

the outcome of nonsurgical

therapy.

Effect noted especially for

moderate-to-deep pockets.

Significant difference in

percentage of pocket reduction

to $<5 \mathrm{~mm}$ following therapy as

well as lower mean. PPD

reduction in obese individuals

compared with nonobese

individuals.

Obese individuals found to

have deeper periodonta

pockets at baseline in all

studies

\section{Nascimento $(2016)^{139}$}

Brazil

Is there a relationship

between obesity and tooth

loss and edentulism? A

systematic review and meta-

analysis

\section{Self-reported BMI (1 study). Tooth loss cut-off points}

BMI cut-off points combining included:

overweight/obesity (2 studies). - 1-5 missing teeth.

BMI WHO Overweight

separate from BMI WHO

Obese (1 study).

- 6-31 missing teeth.

- edentulous (1/4 studies)

- edentulism (1/4 studies).

- $\geq 1$ missing teeth (2/4 studies)
Design: Observational studies.

Sample: Adults.

Search: MEDLINE, Web of

Knowledge, SCOPUS, SciELO.

Language: No restrictions.

Year: No restriction up to and including July 2015.

Aim: To assess the bidirectional

association between tooth

loss/edentulism and obesity
Number of included studies: 16

(12 examining impact of

edentulism on obesity and 4

considering impact of obesity

on edentulism).

Meta-analysis: 4 studies

considering obesity as

exposure.

Obese:

- $\mathrm{OR}=1.49(95 \% \mathrm{Cl}: 1.20$ -

1.86) for any tooth loss.

- $\mathrm{OR}=1.25(95 \% \mathrm{Cl}: 1.10$ -

1.42) for edentulism
Author conclusions

The literature on the effect

of obesity on the

treatment outcome of

onsurgical periodontal

herapy remains

controversial. The data,

however, support the

conclusion that obesity is

not only a factor

associated with poorer

eriodontal health but

might also result in

inferior response to

nonsurgical treatment of

periodontitis
The results indicate a

bidirectional association

between tooth loss and obesity. Considering that

all selected studies were

of cross-sectional study

design, limiting inferences

on temporality,

longitudinal perspective

studies are required to

est the causa

relationship between

tooth loss/edentulism and

obesity or vice versa 
Publication (First author, year, reference number, Country,

Article title)

Nascimento (2016) $)^{140}$

Brazil

Does periodontal treatment

have an effect on clinical and

immunological parameters of

periodontal disease in obese

subjects? A systematic review and meta-analysis

\section{Scope of the review}

Design: Intervention studies.

Sample: Adults.

Search: MEDLINE, EMBASE,

SCOPUS, LILACS, Web of

Knowledge, SciELO

Language: No restrictions.

Year: No restriction up to and

including August 2014

Aim: To systematically review

literature to answer the

questions:

- Is periodontal treatment

effective to improve clinical

and immunological conditions

in obese subjects?

- Do obese subjects present different clinical and immunological response after periodontal therapy when compared with nonobese subjects?

Martens (2017) $\quad$ Design:

Belgium

Association between

overweight/obesity and

periodontal disease in

children and adolescents: a

systematic review and meta-

analysis

Sample: Children, adolescents. Search: Cochrane, MEDLINE,

Web of Science, SCOPUS,

SCIELO, LILACS, SIGLE.

Language: Restricted to

English.

Year: No restriction up to and
Overweight/obesity case

definitions or related

parameters

WHO BMI cut-off points used for defining obese including September 2015.

Aim: To provide a systematic review and meta-analysis investigating the association between overweight/obesity and periodontal disease in terms of clinical periodontal outcomes in children and adolescents
BMI standard categories

adjusted for age, WC, waist/

hip ratio, body fat percentage

and skinfold thickness

PD case definition or related parameters

Results

Author conclusions

Nonsurgical therapy without adjunctive therapies.

Test group: obese.

Control group: nonobese.

Some studies included smokers and others excluded smokers

Various periodontal outcomes employed including gingival bleeding, loss of attachment,

$\mathrm{PI}$, probing pocket depth, $\mathrm{CPI}$, Gl, calculus
Number of included studies: 5

Same studies included as

previous review in table

published by Akram et al ${ }^{131}$

Meta-analysis: three

Same studies included in one meta-analysis (3/5 studies) as noted in previous review in this table by Akram et al ${ }^{130,131}$ Additional meta-analysis of $2 / 5$ studies did not show evidence of a difference between obese and nonobese individuals in

terms of clinical parameters. Obese individuals presented with significantly higher levels of circulating proinflammatory cytokines than nonobese individuals at baseline. No significant differences were found between groups following periodontal therapy

Number of included studies: 12 (11 cross-sectional and 1 longitudinal).

Meta-analysis: 7

Association between PD and obesity: $\mathrm{OR}=1.46(95 \% \mathrm{Cl}$ :

1.20-1.77).

Positive association reported between overweight/obesity and calculus deposits,

gingivitis, gingival bleeding, GI, periodontal index, $\mathrm{BOP}, \mathrm{PI}$, and PPD $>4 \mathrm{~mm}$
Periodontal treatment seems to be effective for improving healing in bese individuals. No differences were observed in periodontal healing between obese and nonobese subjects; however, only a limited the and fragile base of

vidence was available for analysis

The available evidence suggests a significantly positive association

between PD and obesity in children. Pediatric dentists should be aware of periodontal alterations as a potential hazard associated with obesity 
Publication (First author, year, reference number, Country, Article title)

Martinez-Herrera (2017) ${ }^{137}$ Spain

Association between obesity and periodontal disease. A

systematic review of

epidemiological studies and

controlled clinical trials
Scope of the review

Designs: Observational and

experimental studies.

Sample: Adults.

Search: MEDLINE and

EMBASE.

Language: Restricted to

\section{English.}

Year: Published from 2000

onward.

Aim: To offer a systematic

review of the evidence on the

association between obesity

and PD, and of the possible

mechanisms involved in this

relationship

Overweight/obesity case

definitions or related

parameters

All studies included BMI to

define obesity and some

additionally included WC,

WHR or percentage of body

PD case definition or related

parameters

Definition of periodontitis was ased on PPD, CAL, PI, BOP,

$A B L$, self-reporting, and $G I$,

with thresholds not reported
Results

Number of included studies: 29

(19 observational and 9

experimental).

Meta-analysis: None.

Results of observational

studies demonstrate a higher

prevalence of periodontal

disease in obese individuals

than in nonobese individuals

with a stronger association as

obesity level increases.

Some studies support the

association between obesity

and the development of

periodontitis or weight gain

and the development of

periodontitis.

Studies reporting on response

to therapy were inconsistent

so the effect of obesity on

response to periodontal

treatment remains unclear
Author conclusions

The association between obesity and periodontitis was consistent with a compelling pattern of increased risk of periodontitis in overweight or obese individuals. Although the underlying

pathophysiological mechanism remains unclear, it has been pointed out that the development of insulin resistance as a consequence of a chronic inflammatory state and oxidative stress could be implicated in the association between obesity and periodontitis

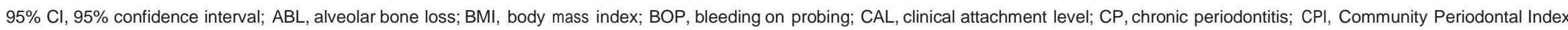

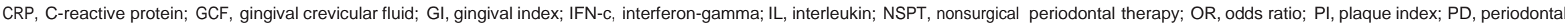

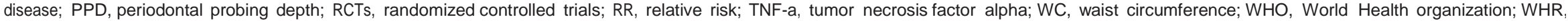
waist/hip ratio. 
TABLE 5 Quality assessment of included publications according to A MeaSurement Tool to Assess systematic Reviews (AMSTAR)

\begin{tabular}{|c|c|c|c|c|c|c|c|c|c|c|c|}
\hline $\begin{array}{l}\text { Author, year } \\
\text { (reference } \\
\text { number) }\end{array}$ & $\begin{array}{l}\text { Was an a } \\
\text { priori design } \\
\text { provided? }\end{array}$ & $\begin{array}{l}\text { Was there } \\
\text { duplicate } \\
\text { study } \\
\text { selection and } \\
\text { data } \\
\text { extraction? }\end{array}$ & $\begin{array}{l}\text { Was a } \\
\text { comprehensive } \\
\text { literature search } \\
\text { performed? }\end{array}$ & $\begin{array}{l}\text { Was the status } \\
\text { of publication (ie, } \\
\text { grey literature) } \\
\text { used as an } \\
\text { inclusion } \\
\text { criterion? }\end{array}$ & $\begin{array}{l}\text { Was a list } \\
\text { of studies } \\
\text { (included } \\
\text { and } \\
\text { excluded) } \\
\text { provided? }\end{array}$ & $\begin{array}{l}\text { Was scientific } \\
\text { quality of the } \\
\text { included } \\
\text { studies } \\
\text { assessed and } \\
\text { documented? }\end{array}$ & $\begin{array}{l}\text { Was scientific } \\
\text { quality of the } \\
\text { included } \\
\text { studies used } \\
\text { appropriately } \\
\text { in formulating } \\
\text { conclusions? }\end{array}$ & $\begin{array}{l}\text { Were the } \\
\text { methods } \\
\text { used to } \\
\text { combine the } \\
\text { findings of } \\
\text { studies } \\
\text { appropriate? }\end{array}$ & $\begin{array}{l}\text { Was the } \\
\text { likelihood of } \\
\text { publication } \\
\text { bias } \\
\text { assessed? }\end{array}$ & $\begin{array}{l}\text { Were } \\
\text { potential } \\
\text { conflicts of } \\
\text { interest } \\
\text { included? }\end{array}$ & $\begin{array}{l}\text { AMSTAR } \\
\text { risk of bias } \\
\text { score }\end{array}$ \\
\hline $\begin{array}{l}\text { Chaffee and } \\
\text { Weston } \\
(2010)^{132}\end{array}$ & Yes & Yes & Yes & No & Yes & Yes & Yes & Yes & Unclear & Yes & $8 / 10$ \\
\hline $\begin{array}{l}\text { Suvan et al } \\
(2011)^{143}\end{array}$ & Yes & Yes & Yes & Yes & Yes & Yes & Yes & Yes & Unclear & Yes & $9 / 10$ \\
\hline $\begin{array}{l}\text { Moura-Grec } \\
\text { et al }(2014)^{138}\end{array}$ & Yes & Yes & Yes & No & Yes & No & Yes & Yes & Unclear & Yes & $7 / 10$ \\
\hline $\begin{array}{l}\text { Keller et al } \\
(2015)^{134}\end{array}$ & Yes & Yes & Unclear & No & Yes & Yes & Yes & $\begin{array}{l}\text { Not } \\
\text { applicable }\end{array}$ & Unclear & Yes & $7 / 10$ \\
\hline Li et al $(2015)^{135}$ & Yes & Yes & Yes & No & Yes & Yes & Yes & Partially & Unclear & No & $6 / 10$ \\
\hline $\begin{array}{l}\text { Nascimento et al } \\
(2015)^{141}\end{array}$ & Yes & Yes & Yes & No & Yes & Yes & Yes & $\begin{array}{l}\text { Not } \\
\text { applicable }\end{array}$ & Unclear & Yes & $8 / 10$ \\
\hline $\begin{array}{l}\text { Papageorgiou } \\
\text { et al }(2015)^{142}\end{array}$ & Yes & Partially & $\begin{array}{l}\text { Databases not } \\
\text { reported }\end{array}$ & $\begin{array}{l}\text { Databases not } \\
\text { reported }\end{array}$ & Yes & Yes & Yes & Yes & Unclear & Yes & $6 / 10$ \\
\hline $\begin{array}{l}\text { Akram et al } \\
(2016)^{130}\end{array}$ & Yes & Yes & Yes & No & Yes & Yes & Yes & Yes & Unclear & Yes & $8 / 10$ \\
\hline $\begin{array}{l}\text { Akram et al } \\
(2016)^{131}\end{array}$ & Yes & Yes & Yes & No & Yes & Yes & Yes & $\begin{array}{l}\text { Not } \\
\text { applicable }\end{array}$ & Unclear & Yes & $7 / 10$ \\
\hline $\begin{array}{l}\text { Gerber et al } \\
(2016)^{133}\end{array}$ & Yes & Yes & Yes & No & Yes & Yes & Yes & $\begin{array}{l}\text { Not } \\
\text { applicable }\end{array}$ & Unclear & Yes & $8 / 10$ \\
\hline $\begin{array}{l}\text { Nascimento et al } \\
(2016)^{139}\end{array}$ & Yes & Yes & Yes & No & Yes & Yes & Yes & Yes & Unclear & Yes & $8 / 10$ \\
\hline $\begin{array}{l}\text { Nascimento et al } \\
(2016)^{140}\end{array}$ & Yes & Yes & Yes & No & Yes & Yes & Yes & Partially & Unclear & Yes & $7 / 10$ \\
\hline $\begin{array}{l}\text { Martens et al } \\
(2017)^{136}\end{array}$ & Yes & Yes & Yes & Yes & Yes & Yes & Yes & Yes & Unclear & Yes & $9 / 10$ \\
\hline $\begin{array}{l}\text { Martinez- } \\
\text { Herrera et al } \\
(2017)^{137}\end{array}$ & Yes & Not reported & Yes & No & Yes & No & No & $\begin{array}{l}\text { Not } \\
\text { applicable }\end{array}$ & Unclear & Yes & $5 / 10$ \\
\hline
\end{tabular}


Health Organization obesity levels I, II, and III. The reported odds ratios were $1.20,1.46,1.78$, and 2.31 , respectively, for each body mass index group, inferring a dose-response association. ${ }^{147} \mathrm{~A}$ statistically significant association between the number of teeth witr deepened pockets and body mass index, body fat percentage, anc waist circumference was demonstrated in a Finnish populatior sample. ${ }^{148}$ While such results warrant further confirmation, more recent investigations have highlighted possible contributing factors. A cross-sectional study conducted in Brazil reported obese cases to have a higher risk of unfavorable periodontal status, with a relative risk of 1.45 for attachment loss. Furthermore, the study compared abdominal obesity with general obesity and reported nc evidence of the effect of the latter on bleeding on probing, whilsi the former was linked to periodontal attachment loss and bleedinc on probing. ${ }^{146}$

Studies of disease onset or progression are infrequent but some have reported on the association between obesity and periodontitis progression, with 5 of 8 supporting a temporal sequence between them. In a 5-year follow-up study of 3590 Japanese individuals, a linear relationship between periodontitis progression anc body mass index was observed. ${ }^{149}$ In 2 studies based on the examination of 1038 US veterans as part of a 40-year health survey, body mass index, waist circumference, and waist circumference-to-height ratio were all significant predictors of periodontitis progression in men, with those who gained weight most rapidly presenting with higher levels of periodontal attachment loss. ${ }^{150,151}$ A recent subgroup analysis of 292 men from the same cohort suggested that the association of central adiposity and progressior of periodontitis is attenuated by genetic variants of proinflammatory interleukin-1. ${ }^{152} \mathrm{~A}$ retrospective analysis of 582 individuals who were part of the Porto Alegre Epidemiological study demonstrated that obese individuals had a higher risk of periodonta attachment loss than nonobese individuals (relative risk $=1.3 \mathrm{E}$ [95\% Cl: 1.04-1.78]). A stratified analysis demonstrated that the association was present for female subjects (relative risk $=1.64$ [95\% confidence interval: 1.11-2.43]) but not for male subjects (relative risk $=1.13$ [95\% confidence interval: $0.75-1.69]$ ]) ${ }^{153}$

Reviews of experimental studies produced varying results and conclusions on the association of overweight/obesity with inferior response to periodontal therapy. This may have occurred for reasons associated with the heterogeneity of the design of the studies included. For example, in one review, all experimental studies included failed to show a positive association. ${ }^{142}$ This review was unique because it included studies on patients with and without type 2 diabetes as well as interventions with adjunctive use of sys. temic antibiotics, each of which may have masked the effects of other factors, such as obesity. Many of the studies investigating the clinical response to periodontal therapy included in the reviews were conducted on a small sample of patients and did not reporl calculation of a sample size; therefore, uncertainty remains regardinc the validity of any difference demonstrated. ${ }^{154-156}$ Meta-analysis of small studies may help overcome this issue; however, it was not possible to do so here because of the high levels of heterogeneity of the included studies in terms of participant inclusion criteria interventions administered, and reported outcomes. For example, 1 study based analysis of the effect of obesity on response to treatment between study groups on sites with probing depths $\geq 4 \mathrm{~mm}$ following treatment no statistically significant difference was shown. ${ }^{157}$ This study was 1 of 3 , included in the review by Gerbel et $\mathrm{al}^{1}{ }^{133}$ which did not demonstrate a difference in periodontal clinical parameters in obese versus nonobese subjects following treat ment. Five of 8 studies in this review did report poorer clinica responses to periodontal treatment in obese compared with nonobese subjects, with the comment that the effect was specifically observed in moderate-to-deep pockets. ${ }^{133}$ Therefore, the difference reported in studies of periodontal therapy may be attributed, in part to baseline severity of disease and thresholds used for analysis.

The included reviews that reported on surrogate measures ot association between periodontitis and obesity (ie, soluble markers demonstrated variability in results; this was partly because of the type of sample selected (gingival crevicular fluid, serum, or plasma', and the specific biomarkers analyzed. One of the reviews focusec solely on assessing the cytokine profiles in gingival crevicular fluic from chronic periodontitis patients with and without obesity; $\varepsilon$ reported a similar cytokine profile (of resistin, adiponecin, leptin interleukin-6, interleukin-8, interleukin-10, and interleukin-1beta) ir obese and nonobese subjects; whereas 5 reported greater differences in some cytokines (resistin, interleukin-8, interleukin-1beta tumor necrosis factor alpha, progranulin, monocyte chemotactic pro tein-4, and lipocalin). ${ }^{130}$ However, some studies did not standardiz $\epsilon$ the methodology of gingival crevicular fluid collection and/or did not report exclusion of participants based on the presence of other systemic diseases, such as diabetes. Changes in clinical parameters following periodontal therapy were not consistently reflective of changes in local or circulating biomarker analyses. ${ }^{130,131,137,140,142}$

Additional reports of biomarker analyses have been published in 2016-2017, some of which are discussed within the context of our current understanding of possible mechanisms of the associatior between obesity and periodontal diseases. Two recent publications investigated the impact of obesity on periimplant inflammation by comparing clinical parameters and either periimplant sulcular fluic or whole saliva. ${ }^{158,159}$ Elangovan et $\mathrm{al}^{159}$ reported a statistically sig. nificant correlation between interleukin-1beta in peri-implant sulcular fluid and waist circumference in 73 periodontal maintenance patients with implants. In a study of 72 men, mean periimplant probing depth and bleeding on probing were statistically significantly higher in obese than in nonobese individuals. Salivary levels of interleukin-1beta and interleukin-6 were also higher in obese individuals.

\section{1 | Possible mechanisms}

Published reports of the possible mechanisms or pathways connecting obesity and periodontal diseases continue to increase our understanding of the complexity of the association. An exaggerated host immune response was initially reported in an experimental model of 
periodontal bone loss. ${ }^{116}$ Clinical evidence confirmed that obese individuals have an increased local inflammatory response ${ }^{160}$ as wel as an altered periodontal microflora. ${ }^{161}$ As the host response to loca bacterial challenge is a key factor in the pathogenesis of periodontitis, differences in the oral microbiome, together with an altered hos response in obesity, have been investigated. Reports of the oral/pe riodontal microbiome composition in overweight and obese individu als remain few in number. A recent observational study reportec obesity to be associated with increased proportions of periodonta pathogens, particularly in patients with obesity and chronic periodontitis, but also in obese individuals without periodontitis. ${ }^{162} \mathrm{Ar}$ investigation of obese individuals after bariatric surgery and ar obese control group with or without periodontitis compared the ora and gastric presence of periodontal pathogens and Helicobacte pylori. Higher frequency of $\mathrm{H}$. pylori was reported in both oral anc stomach environments in patients who had undergone bariatric surgery compared with the obese control group (no surgery). ${ }^{147}$

An alternative mechanism behind this association could be the altered insulin sensitivity state found in obese individuals. ${ }^{163}$ Research suggests that reduced insulin sensitivity coupled with increased production and accumulation of advanced glycation end products at the gingival level in people with diabetes can result ir greater periodontal tissue destruction. ${ }^{39,164}$ Researchers in Spair evaluated 110 obese and 102 lean individuals to determine the role of insulin resistance in the association between obesity and periodontitis. Individuals were divided into nonobese and obese groups with and without insulin resistance, and were then assessed for inflammatory markers and periodontal status. In agreement witr reports presented in the systematic reviews, the results showed that periodontitis was more prevalent and greater in extent and severity in obese subjects than in lean individuals, but was most extensive ir obese subjects with insulin resistance. ${ }^{145}$

Chronic periodontitis has been suggested as a distant source of inflammatory by-products affecting insulin sensitivity. ${ }^{164}$ Tumo necrosis factor alpha is one of the cytokines secreted by viscera adipose tissue in particular, and is implicated in mediation of endo toxin-induced injury in periodontal tissue. ${ }^{165}$ The concentrations of tumor necrosis factor alpha have been reported to be higher ir patients with periodontitis compared with periodontally healthy patients, and have been shown to be reduced following periodonta therapy. ${ }^{161}$ In the previously mentioned study investigating the rol $\epsilon$ of insulin resistance, the levels of tumor necrosis factor alpha anc high sensitivity C-reactive protein were higher in all obese subjects than in nonobese subjects. ${ }^{145}$ Higher levels of tumor necrosis facto alpha in gingival crevicular fluid has been shown to be associatec with a body mass index of $\geq 40 .^{75}$ An association of tumor necrosis factor alpha in gingival crevicular fluid with body mass index has also been demonstrated in obese subjects without periodontitis. I is suggested that tumor necrosis factor alpha found in gingival cre vicular fluid of obese subjects may be secreted from the adipose tissue. $^{164}$

Production of reactive oxygen species resulting in oxidative stress has been investigated as a pathway that may be linked to insulin sensitivity and contributing to a proinflammatory state in obese individuals. An early study showed secretion of reactive oxygen species to be upregulated in adipose tissue and the liver of mice on a high fat diet. ${ }^{166}$ Oxidative stress has also been implicated in severe periodontitis with the suggestion of obesity playing a contributing role. ${ }^{167,168}$ This notion is supported by a study that compared oxidative stress in nonobese and obese subjects who were periodontally healthy or had gingivitis or periodontitis. They found oxidative stress to be higher in the obese plus chronic periodontitis group compared with the nonobese plus chronic periodontitis group higher in the obese plus gingivitis group compared with the nonobese plus gingivitis group; and higher in the periodontally healthy group compared with the periodontally healthy nonobese group. ${ }^{169}$ In a similar study design (4 groups), Suresh et al ${ }^{170}$ also reported more oxidative stress in obese individuals with periodontitis compared with periodontally healthy individuals with obesity.

Leptin, also secreted from adipose tissue, plays a role in immune system function and it is suggested that it plays a role in the pathogenesis of chronic inflammation, with the elevated levels of leptin in obesity believed to contribute to the low-grade inflammation. ${ }^{171}$ Reports of leptin levels in gingival crevicular fluid or saliva have been inconsistent. ${ }^{130}$ Evidence of the association of elevated circulating levels of leptin in obese individuals with periodontitis continue to emerge. Thanakun et $\mathrm{al}^{172}$ reported higher levels of tumor necrosis factor alpha, interleukin-6, leptin, and C-reactive protein in overweight and obese individuals with periodontitis compared with their nonobese counterparts. Adiponectin (anti-inflammatory) was founo to be present at lower levels in overweight/obese individuals with periodontitis. A recent cross-sectional analysis of the levels of resistin, adiponectin, leptin, tumor necrosis factor alpha, and interleukin- 6 in the gingival crevicular fluid of nonobese and obese subjects, with and without periodontitis, concluded that obesity stimulated upregulation of local tumor necrosis factor alpha and serum interleukin-6. the levels of which were highest in the obese group with periodontitis. The levels of adiponectin were decreased, whereas the levels of leptin in gingival crevicular fluid did not differ between groups. ${ }^{173}$ Kanoriya et al $^{174}$ compared gingival crevicular fluid and serum levels of leptin in 70 individuals divided into obese and nonobese groups with or without periodontitis, and found that elevated serum levels of leptin correlated to level of obesity and periodontal health, with the obese periodontitis group demonstrating the highest levels (nonobese periodontally healthy subjects had the lowest levels of leptin), while gingival crevicular fluid levels of leptin were inconsistent among the groups.

Dyslipidemia is a clinical condition proposed to be associatec with periodontitis in addition to obesity, diabetes or vascular disorders. It is suggested that dyslipidemia may exist as a link between obesity and periodontitis. Cury et $\mathrm{al}^{175}$ recently investigated serum levels of lipids in nonobese and obese patients with or without periodontitis. Their results showed that periodontitis and obesity, jointly or individually, were associated with poorer lipid profiles, with obese individuals with periodontitis demonstrating the poorest profiles. Zuza et $\mathrm{al}^{176}$ also reported poorer lipid profiles in obese compared 
with nonobese individuals, with lipid profiles of all subjects with periodontitis being altered following nonsurgical therapy in the obes $\epsilon$ group.

Evidence also exists of a link between different gene expressior profiles and obesity/periodontitis. After inducing experimental periodontitis in obese Zucker rats, Endo and coworkers ${ }^{177}$ concludec that systemic low-grade inflammation after inducing experimenta periodontitis was associated with gene expression of transcribing $\mathrm{C}$. reactive protein, interleukin-6, and tumor necrosis factor alpha in the liver, and C-reactive protein and interleukin- 6 in white adipose tissue, accounting for the higher susceptibility of obese Zucker rats. O'Neill et al $^{178}$ highlighted the important role of toll-like receptors (specifically toll-like receptor 4) as part of the innate immune response regulating macrophages. It was later demonstrated that one means by which toll-like receptor 4 affects macrophages is through the increase or decrease in microRNA-107. ${ }^{179} \mathrm{~A}$ recent report highlights a modulating action of specific microRNAs (microRNA-200b and microRNA-200c) on cell lines including macrophages, resulting in downregulation of the nuclear factor kappalight-chain-enhancer of activated B-cells pathway (which is toll-like receptor 4 dependent). ${ }^{180}$ It is possible that microRNAs modified ir obesity may affect the inflammatory gene targets that predispose tc periodontitis. ${ }^{181}$ The increase in adipokines released from adipocytes triggers macrophage infiltration and the release of cytokines such as interleukin-1beta, interleukin-6, and tumor necrosis factor alpha, lead. ing to insulin resistance and the induction of more inflammation. ${ }^{182}$

In efforts to understand mechanisms of association between obesity and comorbidities, such as periodontal diseases, substances associated with appetite and consumption of nutrients have beer investigated. Ghrelin, one of the hormones secreted by stomach cells plays a role in energy balance through stimulation of appetite. It stimulates growth hormones, but also plays a part in insulin release. A cross-sectional comparison of overweight/obese subjects with nonobese individuals, with and without periodontitis, demonstrated that ghrelin levels in gingival crevicular fluid were significantly lower in individuals with chronic periodontitis and overweight/obesity (median $=118$ pg per site) compared with lean individuals with chronic periodontitis (median $=140 \mathrm{pg}$ per site), or periodontally healthy individuals with overweight/obesity (median $=145 \mathrm{pg}$ per site). ${ }^{183}$

Understanding the complex interplay of all mediators and factors determining a dysregulated or altered homeostasis in inflammatory and immune responses in patients with obesity and periodontitis remains the pursuit of many. Figure 7 is a proposed model outlining current understanding of the signaling pathways that may underpir the relationship between obesity and periodontitis.

The host systemic inflammatory response (mounted by the liver) lies at the center of the various pathways implicated in the association between overweight/obesity and periodontitis. Adipose tissu€ (fat cells) secrete proinflammatory cytokines, such as tumor necrosis factor alpha and interleukin-6, that are key inducers of the acute phase hepatic response, resulting in an increased level of C-reactive protein. Adipocytokine secretions may contribute to this hepatic response, including an increase in reactive oxygen species and free

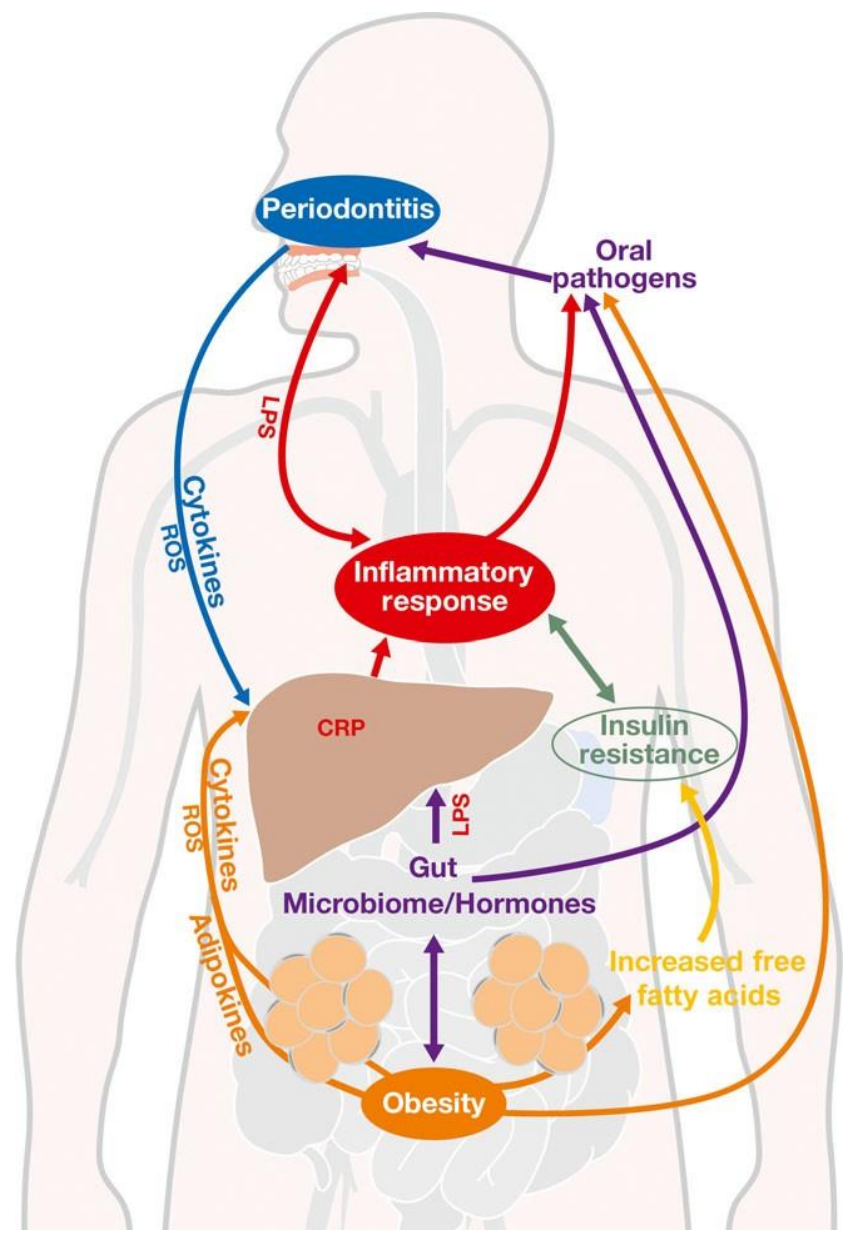

FIGURE 7 Signaling pathway depicting possible links amonc obesity, inflammation and periodontitis. CRP, C-reactive protein LPS, lipopolysaccharide; ROS, reactive oxygen species

fatty acid production (ultimately contributing to insulin resistance), as well as altering the gut microbiome or hormone production. Lastly altered gut permeability with leaking lipopolysaccharide molecules could contribute to this general state of chronic inflammation identified in obese individuals. The resultant increased inflammatory response may, in turn, contribute to alteration of the oral microbiome and/or the local gingival responses to bacteria. Furthermore it has been proposed that obesity is associated with altered microflora via more direct pathways (possibly associated with dietary choices). Once periodontitis is established, the local inflammatory and infectious burden contribute to stimulate the host hepatic response further, via increased systemic dissemination of bacteria end products (lipopolysaccharides) and proinflammatory cytokines (such as tumor necrosis factor alpha and interleukin-6), as well as increased production of reactive oxygen species.

\section{6 | IMPLICATIONS FOR HEALTH PROFESSIONALS}

This meta-review highlights the importance of risk assessment as an essential part of patient care. This concept is based on the 
current understanding that periodontitis is a multifactorial chronic disease with susceptibility varying from one individual to another Specific targeting of therapies according to estimated risk of eacr patient has been proposed as the key to periodontal disease management. $^{50}$

Increasing evidence of obesity as a risk indicator for periodontitis is merely a beginning and does not yet facilitate our understanding of the possible impact for patient care. Questions arise regarding the ways possible to assess or quantify the risk at the level of an individual patient or a tooth. As there are minimal data on the potentia benefit of weight loss in reducing the injurious and additive effect of obesity on periodontal disease, we are unable to choose and recom mend treatment regimens that might work best to compensate for the effect of obesity. With insufficient evidence to guide specific treatment strategies for obese individuals, professionals should not limit clinical judgements to body mass index thresholds or other measures of overweight/obesity, but rather should adhere to known principles of evidence-based and personalized healthcare, making clinical decisions that incorporate individual patient characteristics This demands an increasingly interactive approach to patient care that is focused on healthy lifestyle strategies to address modifiable risk factors supplemented by personalized choices of professionally rendered therapies.

In the context of overweight and obesity, the first step might be for every dental professional to incorporate recordings of height anc weight (with subsequent calculation of body mass index) into daily practice as a part of risk assessment. Additionally, assessing fat distribution by measuring waist circumference could add to risk stratification. Both measures could increase awareness of overweight anc obesity with patients. Similarly to the issue of self-awareness anc reporting of smoking, people tend to underestimate their weight bu tend to overestimate their height, resulting in a misconception o their body mass index. ${ }^{184,185}$ As a consequence of not knowing theil body mass index category, many people may not associate the health risks that they hear are related to a high body mass index as something that is relevant for them.

Likewise, it is proposed that practitioners caring for patients witr obesity should be aware of the possible increased risk of periodontitis in their obese patients, and of its potential to add to the already obesity-related elevation in cardiovascular risk. While obesity man agement may not yet be proven to reduce this, periodontal treat ment certainly has been, and should therefore be a mandatory part of comprehensive care, with possibly even referral for periodonta assessment, as has already been proposed for professionals treatinc patients with diabetes. ${ }^{50}$

In August 2013, The Lancet published a comment statement entitled "A milestone in the response to noncommunicable diseases"; pri orities published in April 2011 were adopted as a Global Action Plar for Prevention and Control of Non-communicable Disease 20132020 by 194 World Health Organization member states. ${ }^{186}$ The action plan proposes a multifaceted collaborative approach to involve health professionals, industry, governments, and the public in reducing the common modifiable risk factors for noncommunicable diseases. ${ }^{187}$ It is suggested that dental professionals could play a role in this collaborative approach.

\section{IMPLICATIONS FOR RESEARCH}

The results of this meta-review suggest that further studies are required to replicate the current findings in specific population samples in order to explore differences according to age, gender, ethnicity, or other possible confounding factors. There are several population-based prevalence studies that show the association at a population level, and further research in this area should be based on published standardized definitions of disease onset, presence, and progression, to understand the magnitude of effect of overweight/obesity. These studies should include more precise phenotyping of body composition and fat distribution, to facilitate understanding of the correlation of each method of assessment with periodontal outcomes.

Sufficient evidence is available to allow the design of studies of possible interventions or treatment regimens as part of the management of oral health in overweight and obese individuals. These studies should include longer follow-up to facilitate understanding of the elements of secondary prevention (periodontal maintenance therapy), and should test interventions and strategies that would be feasible for practitioners in routine care.

Further studies investigating systemic biomarkers are indicatec to advance knowledge of possible mechanisms linking overweight/ obesity and periodontitis. These studies could lead to a better understanding of mechanisms responsible for the association between periodontitis and obesity, and open new avenues for the identification of therapeutic targets in order to maximize treatment responses and disease management.

\section{CONCLUSIONS}

In conclusion, the results presented in this meta-review support the notion of obesity as a factor contributing to periodontal complications. Specifically, the included systematic reviews provide evidence of an association between overweight/obesity and the prevalence: extent, and severity of periodontal diseases, and treatment response in all age groups. In the context of personalized and predictive medical models that suggest the importance of risk assessment, these findings suggest that dental professionals should consider assessment of body mass index as part of daily practice as a means of assessing patients, with the intent to individualize preventive and treatment strategies. Furthermore, assessment and discussion of risk associated with overweight/obesity serves to increase patient awareness of obesity as a chronic disease and serious health condition. Although evidence is lacking to provide specific guidelines to clinicians on the management of periodontal diseases in overweight and obese individuals, awareness of the potential for increased risk of periodontal complications is important. Obesity experts should be aware of the increased risk for 
periodontal complications in overweight/obese patients, and shoulc be prepared to refer patients to dental professionals for further care. Additional prospective studies, to further quantify the magnitude of this association and understand the exact mechanisms: together with studies of periodontal interventions in obese individuals, are merited.

\section{REFERENCES}

1. UK Office of National Statistics. Morality, 2014-based national population projections reference volume, 2016.

2. Petersen PE. Challenges to improvement of oral health in the $21 \mathrm{st}$ century-the approach of the WHO Global Oral Health Programme. Int Dent J. 2004;54(6 Suppl 1):329-343.

3. World Health Organization. The Bangkok Charter for health promotion in a globalized world. Health Promot J Austr. 2005;16(3):168171.

4. WHO. Global status report on noncommunicable diseases, 2014. 1. Chronic Disease - prevention and control. 2. Chronic Disease - epidemiology. 3. Chronic Disease - mortality. 4. Cost of Illness. 5. Delivery of Health Care. http://www.who.int/nmh/publications/ ncd-status-report-2014/en/. Accessed October 31, 2017.

5. Medzhitov R. Inflammation 2010: new adventures of an old flame. Cell. 2010;140(6):771-776.

6. Barbour SE, Nakashima K, Zhang JB, et al. Tobacco and smoking environmental factors that modify the host response (immune sys. tem) and have an impact on periodontal health. Crit Rev Oral Bio Med. 1997;8(4):437-460.

7. Huang EY, Devkota S, Moscoso D, Chang EB, Leone VA. The role of diet in triggering human inflammatory disorders in the moderr age. Microbes Infect. 2013;15(12):765-774.

8. Lim SS, Vos T, Flaxman AD, et al. A comparative risk assessment of burden of disease and injury attributable to 67 risk factors and risk factor clusters in 21 regions, 1990-2010: a systematic analysis for the Global Burden of Disease Study 2010. Lancet. 2012;38C (12):2224-2260

9. Cafiero C, Matarasso S. Predictive, preventive, personalised anc participatory periodontology: 'the 5 Ps age' has already started. EPMA J. 2013;4(1):1-29.

10. Golubnitschaja O, Kinkorova J, Costigliola V. Predictive, preventiv€ and personalised medicine as the hardcore of 'Horizon 2020': EPMA position paper. EPMA J. 2014;5(1):6.

11. Grover A, Joshi A. An overview of chronic disease models: a systematic literature review. Glob J Health Sci. 2014;7(2):210-227.

12. Cafiero C, Matarasso M, Marenzi G, Iorio Siciliano V, Bellia L, Sammartino G. Periodontal care as a fundamental step for an activ€ and healthy ageing. ScientificWorldJournal. 2013;2013:1-7.

13. Bodenheimer T, Lorig K, Holman H, Grumbach K. Patient self-management of chronic disease in primary care. JAMA. 2002;288 (19):2469-2475.

14. NCD-RisC. Trends in adult body-mass index in 200 countries from 1975 to 2014: a pooled analysis of 1698 population-based measurement studies with 192 million participants. NCD Risk Factor Collaboration (NCD-RisC). Lancet. 2016;387(10026):1377-1396.

15. Kershaw EE, Flier JS. Adipose tissue as an endocrine organ. J Clin Endocrinol Metab. 2004;89(6):2548-2556.

16. Lindhe J, Lang N. Clinical periodontology and implant dentistry. 6th Edition, 5th edn. Copenhagen: Munksgaard; 2015.

17. Williams RC. Periodontal disease. N EnglJ Med. 1990;322(6):373382.

18. Lang NP, Adler R, Joss A, Nyman S. Absence of bleeding on probing. An indicator of periodontal stability. J Clin Periodontol. 1990;17 (10):714-721.
19. Page RC. Periodontal diseases: a new paradigm. J Dent Educ. 1998;62(10):812-821.

20. Dye BA, Tan S, Smith V, et al. Trends in oral health status: United States, 1988-1994 and 1999-2004. Vital Health Stat 11. 2007;248:1-92.

21. Eke PI, Dye BA, Wei L, Thornton-Evans GO, Genco RJ. Prevalence of periodontitis in adults in the United States: 2009 and 2010. Dent Res. 2012;91(10):914-920.

22. Kassebaum NJ, Bernabe E, Dahiya M, Bhandari B, Murray CJ Marcenes W. Global burden of severe periodontitis in 1990-2010 a systematic review and meta-regression. J Dent Res. 2014;93 (11):1045-1053.

23. Page RC, Offenbacher S, Schroeder HE, Seymour GJ, Kornman KS. Advances in the pathogenesis of periodontitis: summary of developments, clinical implications and future directions. Periodontol 2000. 1997;14(1):216-248.

24. Van Dyke TE, Kornman KS. Inflammation and factors that may reg ulate inflammatory response. J Periodontol. 2008;79(Suppl 8):15031507.

25. Hajishengallis G. Periodontitis: from microbial immune subversion to systemic inflammation. Nat Rev Immunol. 2015;15(1):30-44.

26. Ebersole JL, Singer RE, Steffensen B, Filloon T, Kornman KS. Inflammatory mediators and immunoglobulins in GCF from healthy, gingivitis and periodontitis sites. J Periodontal Res. 1993;28(6 Pt 2):543-546.

27. Socransky SS, Haffajee AD. Periodontal microbial ecology. Periodontol 2000. 2005;38:135-187.

28. Birkedal-Hansen $\mathrm{H}$. Role of matrix metalloproteinases in human periodontal diseases. J Periodontol. 1993;64(Suppl 5S):474-484.

29. Page RC. The role of inflammatory mediators in the pathogenesis of periodontal disease. J Periodontal Res. 1991;26(3 Pt 2):230-242.

30. Birkedal-Hansen $\mathrm{H}$. Role of cytokines and inflammatory mediators in tissue destruction. J Periodontal Res. 1993;28(6 Pt 2):500-510.

31. Nomura T, Ishii A, Oishi $Y$, Kohma H, Hara K. Tissue inhibitors of metalloproteinases level and collagenase activity in gingival crevicular fluid: the relevance to periodontal diseases. Oral Dis. 1998;4 (4):231-240.

32. Offenbacher S. Periodontal diseases: pathogenesis. Ann Periodontol. 1996;1(1):821-878.

33. Nishikawa M, Yamaguchi Y, Yoshitake K, Saeki Y. Effects of TNFalpha and prostaglandin E2 on the expression of MMPs in humar periodontal ligament fibroblasts. J Periodontal Res. 2002;37(3):167176.

34. Sapna G, Gokul S, Bagri-Manjrekar K. Matrix metalloproteinases and periodontal diseases. Oral Dis. 2014;20(6):538-550.

35. Kornman K. Mapping the pathogenesis of periodontitis: a new look. J Periodontol. 2008;79(Suppl 8):1560-1568.

36. Kocher T, Schwahn C, Gesch D, et al. Risk determinants of periodontal disease-an analysis of the Study of Health in Pomerania (SHIP 0). J Clin Periodontol. 2005;32(1):59-67.

37. Grossi SG, Zambon JJ, Ho AW, et al. Assessment of risk for periodontal disease. I. Risk indicators for attachment loss. J Periodontol. 1994;65(3):260-267.

38. Tomar SL, Asma S. Smoking-attributable periodontitis in the Unitec States: findings from NHANES III. National Health and Nutrition Examination Survey. J Periodontol. 2000;71(5):743-751.

39. Grossi SG, Genco RJ. Periodontal disease and diabetes mellitus: a two-way relationship. Ann Periodontol. 1998;3(1):51-61.

40. McKaig RG, Thomas JC, Patton LL, Strauss RP, Slade GD, Beck JD. Prevalence of HIV-associated periodontitis and chronic periodontitis in a southeastern US study group. J Public Health Dent. 1998;58 (4):294-300

41. Periodontics PotWWi. Section 1. Periodontal diseases: epidemiology and diagnosis. Ann Periodontol. 1996;V1(1):216-222. 
42. Grossi SG, Genco RJ, Machtei EE, et al. Assessment of risk for periodontal disease. II. Risk indicators for alveolar bone loss. J Periodontol. 1995;66(1):23-29.

43. Norderyd O. Risk for periodontal disease in a Swedish adult population. Cross-sectional and longitudinal studies over two decades. Swed Dent J Suppl. 1998;132:1-67.

44. van Winkelhoff AJ, Loos BG, van der Reijden WA, van der Velder $U$. Porphyromonas gingivalis, Bacteroides forsythus and other putative periodontal pathogens in subjects with and without periodonta destruction. J Clin Periodontol. 2002;29(11):1023-1028.

45. Pitiphat W, Merchant AT, Rimm EB, Joshipura KJ. Alcohol consumption increases periodontitis risk. J Dent Res. 2003;82(7):509-513.

46. Kornman KS, Page RC, Tonetti MS. The host response to the microbial challenge in periodontitis: assembling the players. Periodontol 2000. 1997;14(1):33-53.

47. McDevitt MJ, Wang HY, Knobelman C, et al. Interleukin-1 genetic association with periodontitis in clinical practice. J Periodontol. 2000;71(2):156-163.

48. Merchant AT, Pitiphat W, Rimm EB, Joshipura K. Increased physica activity decreases periodontitis risk in men. Eur J Epidemiol. 2003;18(9):891-898.

49. Reinhardt RA, Payne JB, Maze CA, Patil KD, Gallagher SJ, Mattson JS. Influence of estrogen and osteopenia/osteoporosis on clinica periodontitis in postmenopausal women. J Periodontol. 1999;7C (8):823-828.

50. Genco RJ, Borgnakke WS. Risk factors for periodontal disease. Periodontol 2000. 2013;62(1):59-94.

51. Genco RJ, Ho AW, Grossi SG, Dunford RG, Tedesco LA. Relationship of stress, distress and inadequate coping behaviors to periodontal disease. J Periodontol. 1999;70(7):711-723.

52. WHO. WHO Overweight and Obesity Fact Sheet No311. http:// www.who.int/mediacentre/factsheets/fs311/en/. Accessed October 31, 2017.

53. Bray GA. Obesity is a chronic, relapsing neurochemical disease. Int J Obes Relat Metab Disord. 2004;28(1):34-38.

54. WHO. Consultation Obesity: Preventing and Managing the Global Epidemic, 2000.

55. NIH. Clinical Guidelines on the Identification, Evaluation and Treatment of Overweight and Obesity in Adults. 1998.

56. Thompson P. What's Next Now That the AMA has Declared Obesity a Disease? 2013. http://www.amednews.com/article/20130701 house/130709952/1/. Accessed October 31, 2017.

57. Lyon CJ, Law RE, Hsueh WA. Minireview: adiposity, inflammation, and atherogenesis. Endocrinology. 2003;144(6):2195-2200.

58. Kuczmarski RJ, Flegal KM. Criteria for definition of overweight ir transition: background and recommendations for the United States Am J Clin Nutr. 2000;72(5):1074-1081.

59. WHO. Global Database on Body Mass Index, 2008.

60. Lean ME, Han TS, Morrison CE. Waist circumference as a measure for indicating need for weight management. BMJ. 1995;311 (6998):158-161.

61. Vague J. Importance of the measurement of fat distribution in pathology. Bull Mem Soc Med Hop Paris. 1950;66(31-32):1572-1574.

62. Casey AF. Measuring body composition in individuals with intellectual disability: a scoping review. J Obes. 2013;2013:1-6.

63. Wang Y, Rimm EB, Stampfer MJ, Willett WC, Hu FB. Comparison of abdominal adiposity and overall obesity in predicting risk of type 2 diabetes among men. Am J Clin Nutr. 2005;81(3):555-563.

64. Jimenez E. Body composition: assessment and clinical value. Endocrinol Nutr. 2013;60(2):69-75.

65. Gomez-Ambrosi J, Silva C, Galofre JC, et al. Body adiposity anc type 2 diabetes: increased risk with a high body fat percentage even having a normal BMI. Obesity (Silver Spring). 2011;19(7):14391444.
66. Brochu M, Tchernof A, Turner AN, Ades PA, Poehlman ET. Is there a threshold of visceral fat loss that improves the metabolic profile in obese postmenopausal women? Metabolism. 2003;52(5):599-604.

67. Vazquez G, Duval S, Jacobs DR Jr, Silventoinen K. Comparison of body mass index, waist circumference, and waist/hip ratio in pre. dicting incident diabetes: a meta-analysis. Epidemiol Rev. 2007;2气 (1):115-128.

68. Bray GA, Jablonski KA, Fujimoto WY, et al. Relation of central adiposity and body mass index to the development of diabetes in the Diabetes Prevention Program. Am J Clin Nutr. 2008;87(5):12121218.

69. Brochu M, Mathieu ME, Karelis AD, et al. Contribution of the lear body mass to insulin resistance in postmenopausal women with vis. ceral obesity: a Monet study. Obesity (Silver Spring). 2008;1€ (5):1085-1093.

70. Prospective Studies Collaboration, Whitlock G, Lewington S, et al. Body-mass index and cause-specific mortality in 900000 adults collaborative analyses of 57 prospective studies. Lancet. 2009;373 (9669):1083-1096.

71. Siri WE. Body composition from fluid spaces and density: analysis of methods. 1961. Nutrition. 1993;9(5):480-491.

72. Packianathan IC, Fuller NJ, Peterson DB, Wright A, Coward WA Finer $\mathrm{N}$. Use of a reference four-component model to define the effects of insulin treatment on body composition in type 2 diabetes: the 'Darwin study'. Diabetologia. 2005;48(2):222-229.

73. Kotani K, Tokunaga K, Fujioka S, et al. Sexual dimorphism of agerelated changes in whole-body fat distribution in the obese. Int . Obes Relat Metab Disord. 1994;18(4):207-222.

74. Klein S, Allison DB, Heymsfield SB, et al. Waist circumference anc cardiometabolic risk: a consensus statement from shaping America's health: Association for Weight Management and Obesity Preven. tion; NAASO, the Obesity Society; the American Society for Nutrition; and the American Diabetes Association. Obesity (Silver Spring). 2007;15(5):1061-1067.

75. Maury E, Brichard SM. Adipokine dysregulation, adipose tissue inflammation and metabolic syndrome. Mol Cell Endocrinol. 2010;314(1):1-16.

76. Hu FB. Obesity Epidemiology. New York, NY: Oxford University Press; 2008.

77. Padwal RS, Pajewski NM, Allison DB, Sharma AM. Using the Edmonton obesity staging system to predict mortality in a population-representative cohort of people with overweight and obesity. CMAJ. 2011;183(14):E1059-E1066.

78. Sharma AM, Kushner RF. A proposed clinical staging system for obesity. Int J Obes (Lond). 2009;33(3):289-295.

79. Jensen MD, Ryan DH, Apovian CM, et al. 2013 AHA/ACC/TOS guideline for the management of overweight and obesity in adults a report of the American College of Cardiology/American Heart Association Task Force on Practice Guidelines and The Obesity Society. J Am Coll Cardiol. 2014;63(25 Pt B):2985-3023.

80. Falagas ME, Kompoti M. Obesity and infection. Lancet Infect Dis. 2006;6(7):438-446.

81. WHO. Global Health Observatory, 2013. http://www.who.int. Accessed October 31, 2017.

82. Kopelman P. Health risks associated with overweight and obesity. Obes Rev. 2007;8(Suppl 1):13-17.

83. Kopelman P, Jebb SA, Butland B. Executive summary: Foresight 'Tackling Obesities: Future Choices' project. Obes Rev. 2007;8(Suppl 1):vi-ix.

84. Bray GA, Bouchard C. Handbook of Obesity Etiology and Pathophysiology, 2nd edn. New York, NY: Marcel Dekker; 2011.

85. Trayhurn P. The biology of obesity. Proc Nutr Soc. 2005;64(1):31-38.

86. Trayhurn P, Wood IS. Adipokines: inflammation and the pleiotropic role of white adipose tissue. Br J Nutr. 2004;92(3):347-355. 
87. Moleres A, Martinez JA, Marti A. Genetics of obesity. Curr Obes Rep. 2013;2(1):23-31.

88. Cummings DE, Schwartz MW. Genetics and pathophysiology of human obesity. Annu Rev Med. 2003;54(1):453-471.

89. Faroogi IS, O'Rahilly S. Mutations in ligands and receptors of the leptin-melanocortin pathway that lead to obesity. Nat Clin Pract Endocrinol Metab. 2008;4(10):569-577.

90. Ignatieva EV, Afonnikov DA, Saik OV, Rogaev El, Kolchanov NA. A compendium of human genes regulating feeding behavior and body weight, its functional characterization and identification of GWAS genes involved in brain-specific PPI network. BMC Genet. 2016;17 (Suppl 3):158.

91. Nelson MC, Lytle LA, Pasch KE. Improving literacy about energyrelated issues: the need for a better understanding of the concepts behind energy intake and expenditure among adolescents and their parents. J Am Diet Assoc. 2009;109(2):281-287.

92. Reynolds K, Gu D, Whelton PK, et al. Prevalence and risk factors of overweight and obesity in China. Obesity (Silver Spring). 2007;15 (1):10-18.

93. Chaput JP, Klingenberg L, Astrup A, Sjodin AM. Modern sedentary activities promote overconsumption of food in our current obesogenic environment. Obes Rev. 2011;12(5):e12-e20.

94. Huttunen R, Syrjanen J. Obesity and the risk and outcome of infection. Int J Obes (Lond). 2013;37(3):333-340.

95. Tilg $\mathrm{H}$, Moschen AR. Adipocytokines: mediators linking adipose tissue, inflammation and immunity. Nat Rev Immunol. 2006;6(10):772-783.

96. Varady KA, Tussing L, Bhutani S, Braunschweig CL. Degree of weight loss required to improve adipokine concentrations anc decrease fat cell size in severely obese women. Metabolism. 2009;58(8):1096-1101.

97. Ouchi N, Parker JL, Lugus JJ, Walsh K. Adipokines in inflammation and metabolic disease. Nat Rev Immunol. 2011;11(2):85-97.

98. Matsuzawa Y. The role of fat topology in the risk of disease. Int Obes (Lond). 2008;32(Suppl 7):S83-S92.

99. Hotamisligil GS. Inflammation and metabolic disorders. Nature. 2006;444(7121):860-867.

100. Gimeno RE, Klaman LD. Adipose tissue as an active endocrine organ: recent advances. Curr Opin Pharmacol. 2005;5(2):122-128.

101. WHO. Countrywide Integrated Noncommunicable Diseases Intervention (CINDI) Programme, 1995.

102. Leslie WS, Hankey CR, Lean ME. Weight gain as an adverse effect of some commonly prescribed drugs: a systematic review. QJM. 2007;100(7):395-404.

103. Pisinger $\mathrm{C}$, Jorgensen $\mathrm{T}$. Waist circumference and weight following smoking cessation in a general population: the Inter99 study. Prev Med. 2007;44(4):290-295.

104. Malik VS, Schulze MB, Hu FB. Intake of sugar-sweetened beverages and weight gain: a systematic review. Am J Clin Nutr. 2006;84 (2):274-288.

105. McPherson K, Marsh T, Brown M. Tackling Obesities: Future Choices - Modelling Future Trends in Obesity \& Their Impact on Health, 2nd edn. London, UK: UK Government Office for Science; 2007.

106. NICE. Obesity: the prevention, identification, assessment and management of overweight and obesity in adults and children. 2006.

107. Wilding JP. Treatment strategies for obesity. Obes Rev. 2007;8 (Suppl 1):137-144.

108. Dombrowski SU, Knittle K, Avenell A, Araujo-Soares V, Sniehotta FF. Long term maintenance of weight loss with non-surgical interventions in obese adults: systematic review and meta-analyses of randomised controlled trials. BMJ. 2014;348(348):g2646.

109. Saris W. Very low calorie diets and sustained weight loss. Obes Res. 2001;9(S11):295S.

110. Gadde KM, Pritham RY. Pharmacotherapy of obesity: clinical trials to clinical practice. Curr Diab Rep. 2017;17(5):34.
111. Hanipah ZN, Schauer PR. Surgical treatment of obesity and diabetes. Gastrointest Endosc Clin N Am. 2017;27(2):191-211.

112. Koliaki C, Liatis S, le Roux CW, Kokkinos A. The role of bariatric surgery to treat diabetes: current challenges and perspectives. BMC Endocr Disord. 2017;17(1):50.

113. Schauer PR, Nor HZ, Rubino F. Metabolic surgery for treating type 2 diabetes mellitus: Now supported by the world's leading diabetes organizations. Cleve Clin J Med. 2017;84(7 Suppl 1):S47-S56.

114. Labrecque J, Laforest S, Michaud A, Biertho L, Tchernof A. Impac of bariatric surgery on white adipose tissue inflammation. Can . Diabetes. 2017;41(4):407-417.

115. Perlstein MI, Bissada NF. Influence of obesity and hypertension or the severity of periodontitis in rats. Oral Surg Oral Med Oral Pathol. 1977;43(5):707-719.

116. Amar S, Zhou Q, Shaik-Dasthagirisaheb Y, Leeman S. Diet-inducec obesity in mice causes changes in immune responses and bone loss manifested by bacterial challenge. Proc Natl Acad Sci USA. 2007;104(51):20466-20471.

117. Al-Zahrani MS, Bissada NF, Borawskit EA. Obesity and periodonta disease in young, middle-aged, and older adults. J Periodontol. 2003;74(5):610-615.

118. Dalla Vecchia CF, Susin C, Rosing CK, Oppermann RV, Albandaı JM. Overweight and obesity as risk indicators for periodontitis ir adults. J Periodontol. 2005;76(10):1721-1728.

119. Saito T, Shimazaki Y, Koga T, Tsuzuki M, Ohshima A. Relationship between upper body obesity and periodontitis. J Dent Res. 2001;80 (7):1631-1636.

120. Saito $T$, Shimazaki $Y$, Sakamoto $M$. Obesity and periodontitis. $N$ Engl J Med. 1998;339(7):482-483.

121. Torrungruang K, Tamsailom S, Rojanasomsith $\mathrm{K}$, et al. Risk indicators of periodontal disease in older Thai adults. J Periodontol. 2005;76(4):558-565.

122. Wood N, Johnson RB, Streckfus CF. Comparison of body composition and periodontal disease using nutritional assessment techniques: Third National Health and Nutrition Examination Survey (NHANES III). J Clin Periodontol. 2003;30(4):321-327.

123. Shea BJ, Hamel C, Wells GA, et al. AMSTAR is a reliable and valic measurement tool to assess the methodological quality of system. atic reviews. J Clin Epidemiol. 2009;62(10):1013-1020.

124. Walker E, Hernandez AV, Kattan MW. Meta-analysis: Its strengths and limitations. Cleve Clin J Med. 2008;75(6):431-439.

125. Sarrami-Foroushani P, Travaglia J, Debono D, Clay-Williams R Braithwaite J. Scoping meta-review: introducing a new methodology. Clin Transl Sci. 2015;8(1):77-81.

126. DiCenso A, Bayley L, Haynes RB. Accessing pre-appraised evidence: fine-tuning the $5 \mathrm{~S}$ model into a $6 \mathrm{~S}$ model. Evid Based Nurs. 2009;12(4):99-101.

127. Liberati A, Altman DG, Tetzlaff J, et al. The PRISMA statement fol reporting systematic reviews and meta-analyses of studies that evaluate healthcare interventions: explanation and elaboration. BMJ 2009;339(329):b2700.

128. Moher D, Liberati A, Tetzlaff J, Altman DG. Preferred reporting items for systematic reviews and meta-analyses: the PRISMA statement. Ann Intern Med. 2009;151(4):264-269.

129. Miller SA, Forrest JL. Enhancing your practice through evidencebased decision making: PICO, learning how to ask good questions J Evid Based Dent Pract. 2001;1(2):136-141.

130. Akram Z, Abduljabbar T, Abu Hassan Ml, Javed F, Vohra F. Cytokine profile in chronic periodontitis patients with and without obesity: a systematic review and meta-analysis. Dis Markers. 2016; 2016:1-12

131. Akram Z, Safii SH, Vaithilingam RD, Baharuddin NA, Javed F, Vohra $F$. Efficacy of non-surgical periodontal therapy in the management of chronic periodontitis among obese and non-obese patients: a 
systematic review and meta-analysis. Clin Oral Investig. 2016;2C (5):903-914.

132. Chaffee BW, Weston SJ. Association between chronic periodonta disease and obesity: a systematic review and meta-analysis. J Periodontol. 2010;81(12):1708-1724.

133. Gerber FA, Sahrmann P, Schmidlin OA, Heumann C, Beer JH, Sch midlin PR. Influence of obesity on the outcome of non-surgica periodontal therapy - a systematic review. BMC Oral Health. 2016;16(1):90.

134. Keller A, Rohde JF, Raymond K, Heitmann BL. Association between periodontal disease and overweight and obesity: a systematic review. J Periodontol. 2015;86(6):766-776

135. Li LW, Wong HM, Sun L, Wen YF, McGrath CP. Anthropometric measurements and periodontal diseases in children and adolescents: a systematic review and meta-analysis. Adv Nutr. 2015;6 (6):828-841.

136. Martens L, De SS, Yusof MY, Rajasekharan S. Association between overweight/obesity and periodontal disease in children and adoles. cents: a systematic review and meta-analysis. Eur Arch Paediatı Dent. 2017;18(2):69-82.

137. Martinez-Herrera M, Silvestre-Rangil J, Silvestre FJ. Association between obesity and periodontal disease. A systematic review of epidemiological studies and controlled clinical trials. Med Oral Pato Oral Cir Bucal. 2017;22(6):e708-e715.

138. Moura-Grec PG, Marsicano JA, Carvalho CA, Sales-Peres SH. Obesity and periodontitis: systematic review and meta-analysis. Cier Saude Colet. 2014;19(6):1763-1772.

139. Nascimento GG, Leite FR, Conceicao DA, Ferrua CP, Singh A Demarco FF. Is there a relationship between obesity and tooth loss and edentulism? A systematic review and meta-analysis. Obes Rev. 2016;17(7):587-598.

140. Nascimento GG, Leite FR, Correa MB, Peres MA, Demarco FF. Does periodontal treatment have an effect on clinical and immuno logical parameters of periodontal disease in obese subjects? A sys. tematic review and meta-analysis. Clin Oral Investig. 2016;2C (4):639-647.

141. Nascimento GG, Leite FR, Do LG, et al. Is weight gain associatec with the incidence of periodontitis? A systematic review and metaanalysis. J Clin Periodontol. 2015;42(6):495-505.

142. Papageorgiou SN, Reichert C, Jager A, Deschner J. Effect of overweight/obesity on response to periodontal treatment: systematic review and a meta-analysis. J Clin Periodontol. 2015;42(3):247-261.

143. Suvan J, D'Aiuto F, Moles DR, Petrie A, Donos N. Associatior between overweight/obesity and periodontitis in adults. A system. atic review. Obes Rev. 2011;12(5):e381-e404.

144. Kim YS, Kim JH. Body mass index and oral health status in Korear adults: the Fifth Korea National Health and Nutrition Examinatior Survey. Int J Dent Hyg. 2017;15(3):172-178.

145. Martinez-Herrera M, Silvestre FJ, Silvestre-Rangil J, Banuls C Rocha M, Hernandez-Mijares A. Involvement of insulin resistance in normoglycaemic obese patients with periodontitis: A cross-sec tional study. J Clin Periodontol. 2017;44(10):981-988.

146. Nascimento GG, Peres KG, Mittinty MN, et al. Obesity and periodontal outcomes: a population-based cohort study in Brazil. J Periodontol. 2017;88(1):50-58.

147. Pataro AL, Cortelli SC, Abreu MH, et al. Frequency of periodonta pathogens and Helicobacter pylori in the mouths and stomachs of obese individuals submitted to bariatric surgery: a cross-sectiona study. J Appl Oral Sci. 2016;24(3):229-238.

148. Saxlin T, Ylostalo P, Suominen-Taipale L, Mannisto S, Knuuttila M. Association between periodontal infection and obesity: results of the Health 2000 Survey. J Clin Periodontol. 2011;38(3):236-242.

149. Morita I, Okamoto Y, Yoshii S, et al. Five-year incidence of periodontal disease is related to body mass index. J Dent Res. 2011;90 (2):199-202.
150. Gorman A, Kaye EK, Apovian C, Fung TT, Nunn M, Garcia RI. Overweight and obesity predict time to periodontal disease progression in men. J Clin Periodontol. 2012;39(2):107-114.

151. Gorman A, Kaye EK, Nunn M, Garcia RI. Changes in body weight and adiposity predict periodontitis progression in men. J Dent Res. 2012;91(10):921-926.

152. Wilkins LM, Kaye EK, Wang HY, et al. Influence of obesity on periodontitis progression is conditional on interleukin-1 inflammatory genetic variation. J Periodontol. 2017;88(1):59-68.

153. Gaio EJ, Haas AN, Rosing CK, Oppermann RV, Albandar JM, Susin C. Effect of obesity on periodontal attachment loss progression: a 5 -year population-based prospective study. J Clin Periodontol. 2016;43(7):557-565.

154. Al-Zahrani MS, Alghamdi HS. Effect of periodontal treatment on serum C-reactive protein level in obese and normal-weight women affected with chronic periodontitis. Saudi Med J. 2012;33(3):309-314.

155. Altay U, Gurgan CA, Agbaht K. Changes in inflammatory and metabolic parameters after periodontal treatment in patients with and without obesity. J Periodontol. 2013;84(1):13-23.

156. Zuza EP, Barroso EM, Carrareto AL, et al. The role of obesity as a modifying factor in patients undergoing non-surgical periodonta therapy. J Periodontol. 2011;82(5):676-682.

157. Duzagac E, Cifcibasi E, Erdem MG, et al. Is obesity associated with healing after non-surgical periodontal therapy? A local vs. systemic evaluation. J Periodontal Res. 2016;51(5):604-612.

158. Abduljabbar T, Al-Sahaly F, Kellesarian SV, et al. Comparison of peri-implant clinical and radiographic inflammatory parameters anc whole salivary destructive inflammatory cytokine profile among obese and non-obese men. Cytokine. 2016;88:51-56.

159. Elangovan S, Brogden KA, Dawson DV, et al. Body fat indices and biomarkers of inflammation: a cross-sectional study with implications for obesity and peri-implant oral health. Int J Oral Maxillofac Implants. 2014;29(6):1429-1434.

160. Lundin M, Yucel-Lindberg T, Dahllof G, Marcus C, Modeer T. Correlation between TNFalpha in gingival crevicular fluid and body mass index in obese subjects. Acta Odontol Scand. 2004;62(5):273-277.

161. Nishimura F, Iwamoto Y, Mineshiba J, Shimizu A, Soga Y, Murayama $Y$. Periodontal disease and diabetes mellitus: the role of tumor necrosis factor-alpha in a 2-way relationship. J Periodontol. 2003;74(1):97-102.

162. Maciel SS, Feres M, Goncalves TE, et al. Does obesity influence the subgingival microbiota composition in periodontal health anc disease? J Clin Periodontol. 2016;43(12):1003-1012.

163. Reaven GM. The insulin resistance syndrome: definition and dietary approaches to treatment. Annu Rev Nutr. 2005;25(1):391-406.

164. Genco RJ, Grossi SG, Ho A, Nishimura F, Murayama Y. A proposed model linking inflammation to obesity, diabetes, and periodonta infections. J Periodontol. 2005;76(Suppl 11):2075-2084.

165. Gemmell E, Seymour GJ. Cytokine profiles of cells extracted from humans with periodontal diseases. J Dent Res. 1998;77(1):16-26.

166. Matsuzawa-Nagata N, Takamura $\mathrm{T}$, Ando $\mathrm{H}$, et al. Increased oxidative stress precedes the onset of high-fat diet-induced insulin resistance and obesity. Metabolism. 2008;57(8):1071-1077.

167. Bullon P, Morillo JM, Ramirez-Tortosa MC, Quiles JL, Newman HN, Battino M. Metabolic syndrome and periodontitis: is oxidative stress a common link? J Dent Res. 2009;88(6):503-518.

168. D'Aiuto F, Nibali L, Parkar M, Patel K, Suvan J, Donos N. Oxidative stress, systemic inflammation, and severe periodontitis. J Dent Res. 2010;89(11):1241-1246.

169. Atabay VE, Lutfioglu M, Avci B, Sakallioglu EE, Aydogdu A. Obesity and oxidative stress in patients with different periodontal status: a case-control study. J Periodontal Res. 2017;52(1):51-60.

170. Suresh S, Mahendra J, Sudhakar U, Pradeep AR, Singh G. Evaluation of plasma reactive oxygen metabolites levels in obese subjects with periodontal disease. Indian J Dent Res. 2016;27(2):155-159. 
171. likuni N, Lam QL, Lu L, Matarese G, La CA. Leptin and inflammation. Curr Immunol Rev. 2008;4(2):70-79.

172. Thanakun S, Pornprasertsuk-Damrongsri S, Izumi Y. Increased oral inflammation, leukocytes, and leptin, and lower adiponectin in overweight or obesity. Oral Dis. 2017;23(7):956-965.

173. Zimmermann GS, Bastos MF, Dias Goncalves TE, Chambrone L: Duarte PM. Local and circulating levels of adipocytokines in obes $€$ and normal weight individuals with chronic periodontitis. J Periodontol. 2013;84(5):624-633.

174. Kanoriya D, Pradeep AR, Mallika A, Singhal S, Garg V. Correlation of crevicular fluid and serum levels of retinol-binding protein 4 anc leptin in chronic periodontitis and obesity. Clin Oral Investig. 2016;21(7):2319-2325.

175. Cury EZ, Santos VR, Maciel SD, et al. Lipid parameters in obes€ and normal weight patients with or without chronic periodontitis. Clin Oral Investig. 2017;22(1):161-167.

176. Zuza EP, Barroso EM, Fabricio M, Carrareto AL, Toledo BE, Pires R. Lipid profile and high-sensitivity C-reactive protein levels in obes $€$ and non-obese subjects undergoing non-surgical periodontal therapy. J Oral Sci. 2016;58(3):423-430.

177. Endo $\mathrm{Y}$, Tomofuji $\mathrm{T}$, Ekuni $\mathrm{D}$, et al. Experimental periodontitis induces gene expression of proinflammatory cytokines in livel and white adipose tissues in obesity. J Periodontol. 2010;81(4): 520-526.

178. O'Neill LA, Sheedy FJ, McCoy CE. MicroRNAs: the fine-tuners of Toll-like receptor signalling. Nat Rev Immunol. 2011;11(3):163175.

179. Hennessy EJ, Sheedy FJ, Santamaria D, Barbacid M, O'Neill LA. Toll-like receptor-4 (TLR4) down-regulates microRNA-107, increasing macrophage adhesion via cyclin-dependent kinase 6. J Bio Chem. 2011;286(29):531-539.
180. Wendlandt EB, Graff JW, Gioannini TL, McCaffrey AP, Wilson ME. The role of microRNAs miR-200b and miR-200c in TLR4 signaling and NF-kappaB activation. Innate Immun. 2012;18(6):846-855.

181. Luan X, Zhou X, Trombetta-eSilva J, et al. MicroRNAs and periodontal homeostasis. J Dent Res. 2017;96(5):491-500.

182. Grimble RF. Inflammatory status and insulin resistance. Curr Opin Clin Nutr Metab Care. 2002;5(5):551-559.

183. Jentsch HFR, Arnold N, Richter V, Deschner J, Kantyka T, Eick S. Salivary, gingival crevicular fluid and serum levels of ghrelin anc chemerin in patients with periodontitis and overweight. J Periodontal Res. 2017;52(6):1050-1057.

184. Connor GS, Tremblay M, Moher D, Gorber B. A comparison of direct vs. self-report measures for assessing height, weight anc body mass index: a systematic review. Obes Rev. 2007;8(4):307326.

185. Krul AJ, Daanen HA, Choi H. Self-reported and measured weight height and body mass index (BMI) in Italy, the Netherlands anc North America. Eur J Public Health. 2011;21(4):414-419.

186. Chestnov O, Mendis S, Bettcher D. A milestone in the response to non-communicable diseases. Lancet. 2013;382(9891):481-482.

187. Beaglehole R, Bonita R, Horton R, et al. Priority actions for the non-communicable disease crisis. Lancet. 2011;377(9775):14381447. 